\title{
Expression regulation and functional analysis of RGS2 and RGS4 in adipogenic and osteogenic differentiation of human mesenchymal stem cells
}

\author{
Alma Madrigal ${ }^{1,2}$, Lun Tan $^{1}$ and Yuanxiang Zhao ${ }^{1 *}$ (D)
}

\begin{abstract}
Background: Understanding the molecular basis underlying the formation of bone-forming osteocytes and lipidstoring adipocytes will help provide insights into the cause of disorders originating in stem/progenitor cells and develop therapeutic treatments for bone- or adipose-related diseases. In this study, the role of RGS2 and RGS4, two members of the regulators of G protein signaling (RGS) family, was investigated during adipogenenic and osteogenenic differentiation of human mesenchymal stem cells (hMSCs).

Results: Expression of RGS2 and RGS4 were found to be inversely regulated during adipogenesis induced by dexamethasone (DEX) and 3-isobutyl-methylxanthine, regardless if insulin was present, with RGS2 up-regulated and RGS4 down-regulated in response to adipogenic induction. RGS2 expression was also up-regulated during osteogenesis at a level similar to that induced by treatment of DEX alone, a shared component of adipogenic and osteogenic differentiation inducing media, but significantly lower than the level induced by adipogenic inducing media. RGS4 expression was down-regulated during the first $48 \mathrm{~h}$ of osteogenesis but up-regulated afterwards, in both cases at levels similar to that induced by DEX alone. Expression knock-down using small interfering RNA against RGS2 resulted in decreased differentiation efficiency during both adipogenesis and osteogenesis. On the other hand, expression knock-down of $R G S 4$ also resulted in decreased adipogenic differentiation but increased osteogenic differentiation.

Conclusions: RGS2 and RGS4 are differentially regulated during adipogenic and osteogenic differentiation of hMSCS. In addition, both RGS2 and RGS4 play positive roles during adipogenesis but opposing roles during osteogenesis, with RGS2 as a positive regulator and RGS4 as a negative regulator. These results imply that members of RGS proteins may play multifaceted roles during human adipogenesis and osteogenesis to balance or counterbalance each other's function during those processes.
\end{abstract}

Keywords: RGS2, RGS4, Human mesenchymal stem cells (hMSCs), Adipogenesis, Osteogenesis

\section{Background}

Advancement in understanding adipose and bone tissue biology will help develop new strategies for the prevention and intervention of adipose- and bone-related diseases, including obesity and osteoporosis. Adipogenesis

\footnotetext{
*Correspondence: zhao@cpp.edu

${ }^{1}$ Biological Sciences Department, California State Polytechnic University

at Pomona, 3801 W. Temple Ave., Pomona, CA 91768, USA

Full list of author information is available at the end of the article
}

and osteogenesis are processes in which uncommitted stem cells differentiate into mature adipocytes or osteocytes, respectively. Over the past two decades or so, many individual adipogenic regulators have been independently uncovered, which include specific signaling pathways (TGF $\beta / B M P, W n t$, Hedgehogs, MAPK and JAK-STAT3 signaling etc.), growth factors or cytokines (FGF1/2, RB, ZFP423 and SOX9 etc.), transcription factors (C/EBPs, PPARy, KLF4, FOXC2 and GATA2/3 etc.), GTPase proteins and its regulators (RHO and ROCK 
etc.), epigenetic regulators and microRNAs etc. [1-3]. Most significantly, C/EBP $\alpha$ (CCAAT/enhancer binding protein alpha) and PPAR $\gamma$ (peroxisome proliferatoractivated receptor gamma) were identified as two key transcriptional factors, which when over-expressed could dictate adipogenic cell fate in both murine preadipocyte cell line 3T3L1 and hMSCs [4-8]. Similarly, many signaling pathways including TGF $\beta / B M P$ signaling, Wnt signaling, $\mathrm{HH}$ signaling, Notch signaling, PI3K signaling, and ERK1/2 and p38 MAPK mediated signaling, as well as growth factors (FGFs), hormones (Estrogen and Parathyroid hormone), transcription factors (Runx2 and Osterix), bone matrix proteins (ALP, BSP, OCN, OPN, COL 1) and microRNAs etc. have been implicated in osteogenic regulation [9-12]. Among those, Runx 2 and Osterix were identified as master regulators of osteoblast commitment, proliferation and maturation, as knockout mice deficient in either Runx2 or Osterix failed to form bone due to lack of osteoblasts [13, 14]. In addition, overexpression of Runx2 helps stimulate transdifferentiation of 3T3L1 preadipocytes into bone-forming osteoblasts in vitro [15]. Runx2 regulates the expression of osteogenic markers ALP, BSP, OCN, OPN and COL 1, as well as Osterix, though Osterix can be induced by signaling pathways independent of Runx2 [16].

While the adipogenic and osteogenic lineage commitment clearly involve distinct master transcriptional regulators and downstream genetic cascades, in many cases, they are also regulated by the same signaling pathways (Ex. Wnt, IGF and HH signaling) and genes [17, 18]. For examples, many of the siRNA hits identified through a high throughput screen were found to promote osteogenic differentiation but inhibited adipogenesis, and cAMP was identified to play opposing roles in osteogeneis vs. adipogenesis [17]. In addition, there appears to be an inverse relationship between adipogenesis and osteogenesis, with one process inhibiting the other [19]. Some medical drugs such as Rosiglitazone have been found to increase adiposity at the expense of bone formation [2023]. Aging has also been shown to increase bone marrow adiposity but decrease bone mass and strength, which appear to be mediated through regulators of both adipogenesis and osteogenesis [24-28]. These findings indicate that studying the role of potential regulators involved in both adipogeneis and osteogenesis is important in order to better understand the relationship between adipose and bone biology and the etiology of their disease states.

Human mesenchymal stem cells (hMSCs) are a type of adult stem cell that exist in multiple tissues in the body, including adipose tissue, bone marrow and peripheral blood, and play important roles in maintaining normal tissue homeostasis. They can be isolated, expanded and differentiated in vitro into a number of specialized cell types including adipocytes and osteocytes, which makes them an excellent in vitro cell model for studying human adipogenesis and osteogenesis [29]. Using a simple cocktail of adipogenic inducing media (AIM) containing dexamethasone (DEX), 3-isobutyl-1-methylxanthine (IBMX) and insulin, hMSCs can be induced to differentiate into mature adipocytes $[29,30]$. Similarly, using a cocktail of osteogenic inducing media (OIM) containing DEX, ascorbic acid-2-phosphate and beta-glycerophosphate, hMSCs can undergo osteogenesis and become mature osteocytes $[17,29]$. Due to their ability to differentiate into a variety of mature cell types, low allogeneic immune response and low tumorigenicity in graft recipients, hMSCs have been of great interests to researchers exploring cell-based therapies as well and is the most prevalent cell type used in ongoing stem-cell based clinical trials [31]. In addition to advancing our basic understanding of adipose and bone tissue biology, the potential therapeutic application of hMSCs in adipose and bone tissue engineering makes it even more relevant to use these cells for studying human adipogenesis and osteogenesis [32-35].

Using adipose tissue derived hMSCs as an in vitro model for adipogenic differentiation, we identified through microarray analysis two members of the regulator of G protein signaling (RGS) family, RGS2 and RGS4, which were differentially regulated upon adipogenic induction (unpublished data). Both RGS2 and RGS4 belong to the B/R4 subfamily of RGS proteins family characterized by a conserved 120 aas RGS domain flanked by short amino and carboxyl termini [36]. They are intracellular proteins primarily recognized for their GTPase activating protein (GAPs) activity, which inhibits G-protein coupled receptor (GPCR) signaling by deactivating the $\mathrm{G} \alpha$ subunits of heterotrimeric $G$ proteins

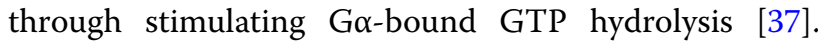
RGS2 possesses intrinsic GAP activity that is selective for $\mathrm{G}_{\mathrm{q}}$-class $\mathrm{G \alpha}$ subunits, whereas RGS4 has intrinsic GAP activity for both $G_{q}$ and $G_{i / o}$-class $G \alpha$ subunits [38, 39]. As GPCRs comprise the largest cell surface receptors in mammalian cells, GPCR mediated signaling regulates a wide array of cellular processes including proliferation, differentiation, cell death and numerous physiological functions. Unsurprisingly, RGS proteins are expressed in essentially all cell types, tissues and organ systems and have been implicated in various physiology and disease as well, including hemapopoiesis, synaptic signaling plasticity in the brain/anxiety disorder, smooth muscle contraction and relaxation/hypertension, kidney function, cancer migration and invasion [40-45]. Aside from G-protein dependent activity, RGS proteins are also involved in G-protein independent signaling [46].

Despite knowledge in a wide array of biological events involving RGS proteins, our current understanding of 
the role of RGS proteins during human adipogenesis and osteogenesis is very limited. No study thus far has directly examined the role of RGS in osteogenesis, though past studies have revealed an important role of RGS proteins during bone remodeling by modulating osteoclastogenesis [47, 48]. RGS2 was also found to be expressed in rat metaphyseal and diaphyseal bone and cultured mouse osteoblasts, implicating potential function in bone development [47]. In addition, several GPCRs involved in osteogenesis including parathyroid hormone 1 receptor (PTH1R), frizzled (Fz) and calcium sensing receptor (CsR) are expressed in osteoblasts and regulated by RGS proteins [49]. On the other hand, a more direct relationship between RGS proteins and adipose physiology have been established through knock-out mice models and in vitro studies in murine cell lines. Loss of RGS5 in mice resulted in exacerbated obesity, hepatic steatosis, inflammation, and insulin resistance while loss of RGS2 in mice leads to lower weights, reduced fat deposits, decreased serum lipids, and lower leptin levels $[50,51]$. Preadipocytes isolated from $R G S 2-/-$ mice showed lower expression levels of adipogenic markers including PPARY $\gamma$, CEBP $\alpha$, and leptin. In another study using NIH-3T3 mouse preadipocyte cells, RGS2 overexpression promoted adipogensis in the presence of a ligand for PPAR $\gamma$ [52]. RGS4 knockout mice also showed a significantly lower body weight compared to wild type mice [53], though in a separate study, these mice showed no significant effect on body weight but had increased circulating free fatty acid, indicating a role in lipolysis [54]. The role of RGS2 or RGS4 in human adipogenesis however remains unknown.

In this study, we characterized the temporal expression patterns of both RGS2 and RGS4 genes during adipogenic and osteogenic differentiation of hMSCs, as well as their function during both processes. Our results demonstrated that RGS2 and RGS4 are differentially regulated during adipogenic and osteogenic differentiation of hMSCs, with both playing positive roles during adipogenesis but opposite roles during osteogenesis.

\section{Results}

\section{Characterization of adipose-derived hMSCs}

\section{by clonogenicity and molecular marker expression}

The adipose-derived hMSCs used in this study were obtained from a commercial source (see "Methods"). Previously we have shown that these cells were able to differentiate into adipocytes and osteocytes in response to appropriate external stimuli [55]. To gain a better understanding of these cells, both clonogenicity of these cells as well as the expression of three known hMSCs markers, CD73, CD90 and CD105, were examined at passage 4 (P4), the same passage cells used in all subsequent experiments.
Of 3 independent repeats, the average clonogenicity (number of cells per clone is $>50$ ) was determined to be $8 \%$ ( $\pm 0.67 \%$ ) (Additional file 1: Figure S1).

To determine the expression of the three marker genes, immunostaining was carried out first. Both CD73 and CD105 were shown to be expressed almost ubiquitously, especially with CD105 whose expression in each individual cell can be easily discerned (Additional file 2: Figure S2, top 2 rows). Immunostaining with antibodies against CD90 from two different sources appeared to be challenging despite several attempts with various conditions, which had also been predicted due to indicated formalin sensitivity of epitope recognized by the antibody. Flow cytometry was subsequently used to analyze the expression of CD90. As control, cells were also co-stained with antibody against CD73. About 96 and $95.72 \%$ of cells independently express CD73 and CD90 respectively, and about $95 \%$ of cells co-express both (Additional file 2: Figure $\mathrm{S} 2$, bottom 2 rows).

In conclusion, the above results indicate that the adipose-derived hMSCs used in this study demonstrated $8 \%$ clonogenicity, with about $95 \%$ of them expressing all three markers, CD73, CD90 and CD105.

\section{Temporal expression of RGS2 and RGS4 during adipogenesis and osteogenesis}

Our initial interest in members of the regulator of $G$ protein signaling (RGS) family began with a microarray analysis aimed at identifying novel regulators of human adipogenesis (unpublished data). Briefly, the expression profiles of hMSCs exposed to adipogenic differentiation condition (IBMX + DEX + insulin in growth media) was compared to undifferentiated hMSCs at 36 and $72 \mathrm{~h}$ post induction. Through this analysis, RGS2 and RGS4 were found to be significantly up- and down-regulated respectively during early adipogenesis, with RGS2 up regulated by 15 -folds, and RGS4 down regulated by 100 -folds at $72 \mathrm{~h}$ post induction. Because adipose and bone cells share common progenitor cells and there are shared regulators between adipogenesis and osteogenesis [17, 18], we expanded our interest in understanding the role of RGS2 and RGS4 in both adipogenesis and osteogenesis.

We first sought to determine the temporal expression pattern of RGS2 and RGS4 during both osteogenic and adipogenic differentiation of hMSCs. For adipogenesis, hMSCs were cultured in hyclone growth media (CM) supplemented with IBMX $(0.45 \mu \mathrm{M})$, DEX $(1 \mu \mathrm{M})$, and insulin $(10 \mu \mathrm{g} / \mathrm{ml})$, which is abbreviated as adipogenic inducing media (AIM). For osteogenesis, cells were cultured in CM supplemented with DEX $(0.2 \mu \mathrm{M})$, $\beta$-glycerophosphate $(10 \mathrm{mM})$, and ascorbic acid-2-phosphate $(0.05 \mathrm{mM})$, which is abbreviated as osteogenic inducing media (OIM). DEX is a common component 
used in hMSC differentiation into adipocyte, osteocyte, and chondrocytes, and is thought to be necessary to potentiate differentiation and prevent apoptosis $[56,57]$. Therefore, to also dissect the role of individual component of differentiation inducing cocktails on the expression of RGS2 and RGS4, RT-PCR was performed on both genes in hMSCs cultured in 8 different media treatments that include CM (control group), DEX $(0.2 \mu \mathrm{M})$, DEX $(1 \mu \mathrm{M})$, DEX $(0.2 \mu \mathrm{M})+$ IBMX, AIM with $0.2 \mu \mathrm{M}$ DEX, AIM with $1 \mu \mathrm{M}$ DEX, OIM with $0.2 \mu \mathrm{M}$ DEX, and OIM with $1 \mu \mathrm{M} \mathrm{DEX}$, at eight different time points including D0.5, D1, D1.5, D2, D4, D5, D6 and D7 post initial treatment, with media change at 48 -h intervals. All treatment group media was made in CM. Transcript level of $R G S 2$ and RGS4 in each treatment group were normalized to that of a housekeeping gene HSP90 (internal control) and compared to its normalized level in CM control at corresponding time point.

As expected, expression of $C / E B P \alpha$ and $P P A R \gamma$, two well-known master regulators for adipogenic lineage commitment, were both highly up regulated in AIM treated cells (Fig. 1a, b). Similarly, expression of LPL, a relatively later stage adipogenic marker encoding a lipoprotein lipase that breaks down lipids [58]. was also highly enriched in AIM treated cells (Fig. 1c) (Expression of LPL was undetectable in CM groups, so its
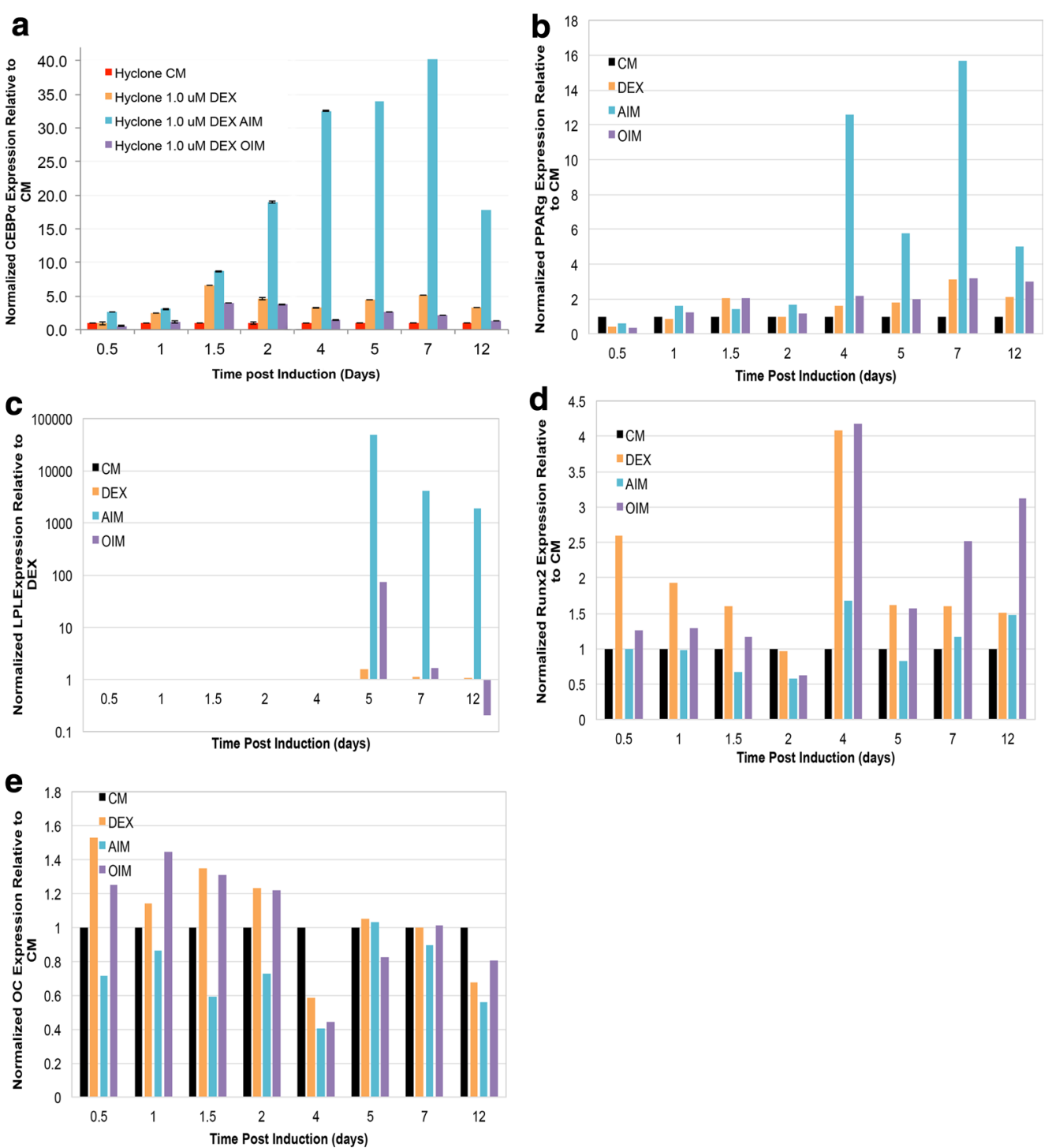

Fig. 1 Temporal expression of adipogenic and osteogenic markers in AIM and OIM treatments. Expression of adipogenic markers C/EBPa (a), PPARY (b), LPL (c) and osteogenic markers Runx2 (d) and Osteocalcin (OC) (e) in control Hyclone CM, Hyclone CM based $1 \mu$ M DEX (Hyclone $1 \mu$ M DEX), Hyclone CM based AIM with $1 \mu$ M DEX (Hyclone $1 \mu$ M DEX AIM), and Hyclone CM based OIM with $1 \mu$ M DEX (Hyclone $1 \mu$ M DEX OIM) was examined at D0.5, D1, D1.5, D2, D4, D5, D6 and D7 post initial treatment 
expression in AIM and OIM treated cells was compared to its expression in DEX treated cells). On the other hand, expression of Runx2, a master regulator for osteogenic differentiation [14], was expressed at a higher level in OIM treated cells relative to AIM treated cells, especially after D4 (Fig. 1d). However, expression of osteocalcin (OC), which encodes a bone specific protein synthesized by osteoblast and serves as a marker of osteogenic maturation [59], appeared to be only slightly upregulated in DEX and OIM treated cells compared to its expression in AIM before D4, but reached to a similar level across all treatment groups thereafter (Fig. 1e).

Expression of RGS4 remained high in hMSCs cultured in CM throughout D0.5 to D7, but was differentially regulated in response to adipogenic induction (DEX + IBMX or AIM) vs. osteogenic induction (OIM) (Fig. 2a). Starting as early as D0.5, adipogenic induction by DEX + IBMX or AIM, regardless of DEX concentrations, resulted in down regulation of RGS4 by 2.5- to 5 -folds. By D1, RGS4 was barely detectable and remained significantly down-regulated throughout the remaining treatment duration (Fig. 2). In OIM treatments, again regardless of DEX concentrations, RGS4 expression followed a similar pattern as in DEX treatment alone, first slightly downregulated by 1.5 - to 3.3 -folds between D0.5 and $\mathrm{D} 2$ and then upregulated by up to 3.75 -fold between D4 and D7 (Fig. 2a). Overall, RGS4 expression is down regulated by all adipogenic treatment conditions starting as early as $12 \mathrm{~h}$ post treatment initiation, and upregulated by osteogenic treatments starting $\mathrm{D} 4$ in a pattern similar to DEX only treatment.

Expression of RGS2 is upregulated by all treatment types relative to its expression in control CM, though the degree of changes differs between adipogenic conditions and the other treatment conditions at certain time points (Fig. 2b). In contrast to RGS4, RGS2 expression was very low in hMSCs cultured in CM (Fig. 2b). Similar to RGS4 however, RGS2 expression in OIM followed the same pattern as its expression in DEX treatment alone, regardless of DEX concentrations. At D0.5, RGS2 was upregulated by 3.5 - to 5 -folds across all treatment groups compared to CM. At D1, RGS2 expression was induced to $12-$ to 14-folds higher in all adipogenic treatment conditions as compared to CM, which is about twice its level in DEX alone or OIM conditions. Between D1.5 and D4, its overall expression level was reduced across all treatment groups as compared to D1, but remained about twofold higher in all adipogenic conditions as compared to OIM or DEX alone. By D5, there was no significant difference across different treatment groups and by D6, RGS2 expression across all treatment groups dropped to similar levels as in CM control. Overall, expression of RGS2 is upregulated by all treatment types throughout D0.5 to D5, with significantly greater gain in adipogenic conditions (around twofolds) compared to the other treatment conditions between D1 and D4.

In conclusion, expression of both RGS2 and RGS4 in OIM treatment was regulated in parallel to that by dexamethasone treatment alone, regardless of DEX concentrations, indicating that the other two components in OIM media, AA-2-P and $\beta$-glycerophosphate, had no significant effect on RGS2 and RGS4 expression. RGS2 was upregulated by both DEX and OIM starting as early as D0.5 and subsiding by D6, whereas RGS4 was slightly downregulated by DEX and OIM during D0.5 to D2 but up-regulated afterwards. On the contrary, expression of
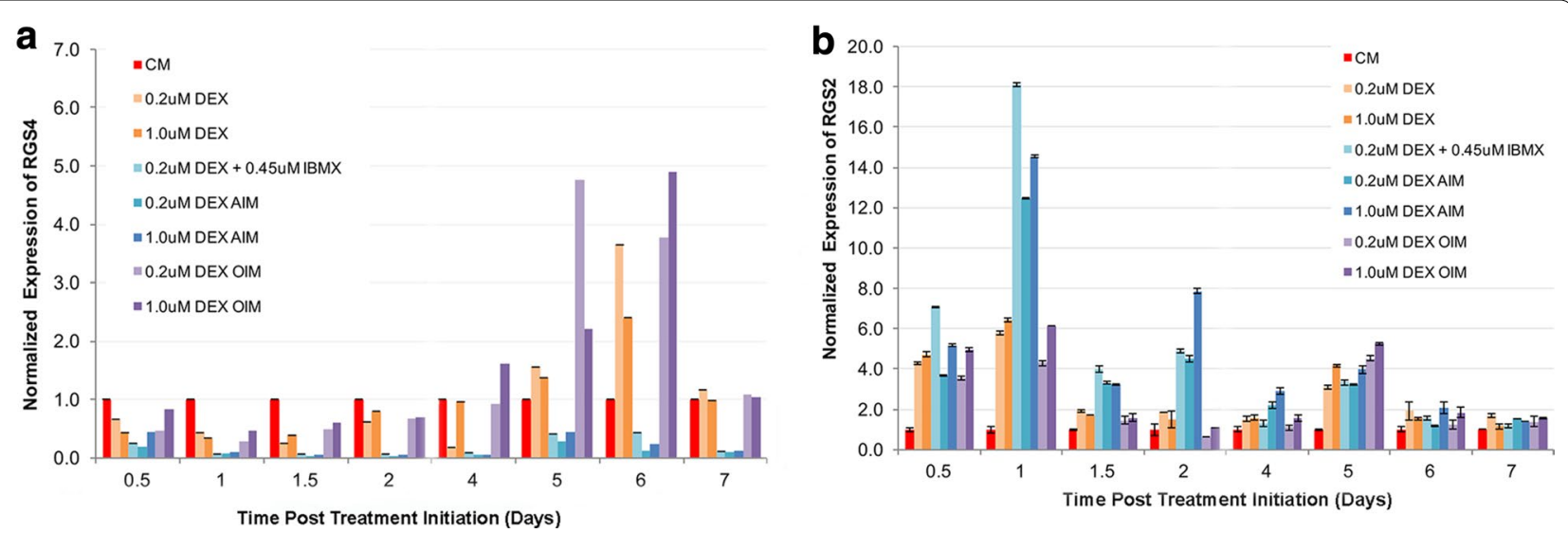

Fig. 2 Temporal expression of RGS4 and RGS2 in AIM and OIM treatments. Expression of RGS4 (a) and RGS2 (b) was examined by RT-PCR in hMSCS cultured in 8 different media treatments, including CM (control), DEX $(0.2 \mu \mathrm{M})$, DEX $(1 \mu \mathrm{M})$, DEX $(0.2 \mu \mathrm{M})+\mathrm{IBMX}$, AIM with $0.2 \mu \mathrm{M}$ DEX, AIM with $1 \mu \mathrm{M}$ DEX, OIM with $0.2 \mu \mathrm{M}$ DEX, and OIM with $1 \mu \mathrm{M}$ DEX. Expression in each treatment condition was examined at eight different time points, including D0.5, D1, D1.5, D2, D4, D5, D6 and D7 post initial treatment. Graphs represent average gene expression level normalized to that of HSP90 and set relative to CM control at each given time point $(\mathrm{n}=2)$. $\mathbf{a}$ Graph of RGS4 expression. $\mathbf{b}$ Graph of RGS2 expression 
both RGS2 and RGS4 differs significantly in adipogenic conditions as compared to in DEX alone, regardless of DEX concentration, indicating that IBMX and/or insulin exerted additional effect on their expression. Since their expression in IBMX + DEX inducing media is highly similar as in AIM, it suggests that IBMX, and not insulin, exerts such effect. Similar to DEX treatment, adipogenic treatment enhanced RGS2 expression until D6, but at significantly higher level (around twofolds) than DEX alone during D1 to D4. For RGS4 expression however, adipogenic treatment not only significantly inhibited the expression of RGS4 at a much greater level than DEX alone during D0.5 to D2 (near undetectable level), but also continued to downregulate its expression throughout the remaining course when it was being upregulated by DEX alone. Hence regulation of RGS2 and RGS4 expression were completely opposite to each other in adipogenic conditions.

\section{Regulation of RGS2 and RGS4 during adipogenic and osteogenic differentiation is independent of media type}

Since the Hyclone growth media (CM) used in composing the AIM media for adipogenic induction is a proprietary product that might contain unknown growth factor supplement, we wondered whether expression of RGS2 and RGS4 would remain similar in AIM based on a different growth media. Temporal expression pattern of RGS2 and RGS4 was then re-examined in parallel in culture conditions based on Hyclone CM, heat-inactivated fetal bovine serum (FBS) in DMEM complete media (HIFBS CM), or FBS in DMEM complete media (FBS CM). The conditions included Hyclone CM or HI-FBS CM, Hyclone CM DEX $(1 \mu \mathrm{M})$ or HI-FBS CM DEX $(1 \mu \mathrm{M})$, Hyclone CM based AIM or HI-FBS CM based AIM or FBS CM based AIM (all with $1 \mu \mathrm{M}$ DEX), and Hyclone CM based OIM (with $1 \mu \mathrm{M}$ DEX) at D0.5, D1, D1.5, D2, D3 and D4 post adipogenic initiation (Additional file 3: Figure S3).

Similar to previous results, expression of RGS4 was downregulated by both DEX alone and AIM from D0.5 to D3, regardless whether they were Hyclone CM or HIFBS CM based, however, its level was significantly higher in Hyclone CM based AIM than in HI-FBS CM based AIM at day 1 and day 2 (Additional file 3: Figure S3A). Similarly, RGS2 expression was upregulated by both DEX alone and AIM, regardless whether they were Hyclone CM or HI-FBS CM based. However, its surge in Hyclone CM based AIM was significantly greater (by up to twofolds) than that in HI-FBS CM based AIM (Additional file 3: Figure S3B). As a parallel control, expression of RGS2 and RGS4 in Hyclone OIM remain similar to previously described results.
In conclusion, the above results indicate that regulation of RGS2 and RGS4 during adipogenic differentiation is independent of media type, though the degree of change could vary. Next, we sought to determine the role of RGS4 and RGS2 during adipogenic and osteogenic differentiation through siRNA mediated gene silencing.

\section{Expression knockdown of RGS2 and RGS4 in differentiating ad-hMSCs by reverse siRNA transfection}

Previously, we identified XtremeGENE siRNA transfection reagent as a highly efficient SiRNA delivery system in bone marrow derived hMSCs [17]. To confirm the effectiveness of this transfection reagent in adipose derived hMSCs (Ad-hMSCs), Ad-hMSCs were reverse transfected with siTOX or control siRNA SiCON at $16.5 \mathrm{nM}$. The former activates cellular death response while the latter does not target any known genes in the human genome. Total cell numbers at days 1, 2, 6, and 12 post transfection were compared between siTOX and siCON. SiTOX reduced cell number by $23 \%$ (day 1 ), $84 \%$ (day 2), $83 \%$ (day 6), and $72 \%$ (day 12) compared to $s i C O N$, without any noticeable cytotoxic effect in siCON treated cells (Additional file 4: Figure S4). Based on the above results, future experiments were conducted using $16.5 \mathrm{nM}$ of siRNA to achieve $80-90 \%$ of transfection efficiency.

To examine the role of RGS2 and RGS4 in ad-hMSCs differentiation into adipocytes and osteocytes, siRNAs commercially validated against two different regions of the RGS4 mRNA (siRGS4-8 and siRGS4-10) and RGS2 $m R N A$ (siRGS2-2 and siRGS2-3) were tested. SiRNA was transfected into cells at 2 days (D-2) prior to adipogenic differentiation initiation (D0 AIM). Expression of RGS2 and RGS4 in transfected ad-hMSCs were examined at day $1,3,5,7$, and 12 post adipogenic initiation with AIM containing 1.0 $\mu \mathrm{M}$ DEX or osteogenic initiation with OIM containing 0.2 $\mu \mathrm{M}$ DEX (Fig. 3). Expression level of $R G S 2$ and RGS4 in each treatment group was normalized against the expression level of HSP90 and then graphed relative to its normalized expression in siCON control group at the same time point.

In samples treated with AIM, RGS4 mRNA was significantly $(\mathrm{p}<0.05)$ lower at day $3(39 \%), 5(32 \%)$, and $7(48 \%)$ in siRGS4-8 treatment groups compared to siCON controls (100\%) (Fig. 3a, b). Similarly, in siRGS410 treatment groups, RGS4 $m R N A$ was also significantly $(\mathrm{p}<0.05)$ lower at day $3(56 \%), 5(36 \%), 7(31 \%)$ and 12 (65\%) compared to controls (100\%) (Fig. 3a, b). In samples treated with OIM, expression of RGS4 was significantly $(\mathrm{p}<0.05)$ lower in siRGS4-8 samples at day 1 (51\%), 3 (39\%), 7 (41\%) and 12 (78\%) compared to siCON (100\%) (Fig. 3c, d). Likewise, in siRGS4-10 treatments, RGS4 mRNA was significantly ( $\mathrm{p}<0.05$ ) lower at day 1 (65\%), and 3 (23\%), 7 (57\%) and 14 (76\%) (Fig. 3c, d). 


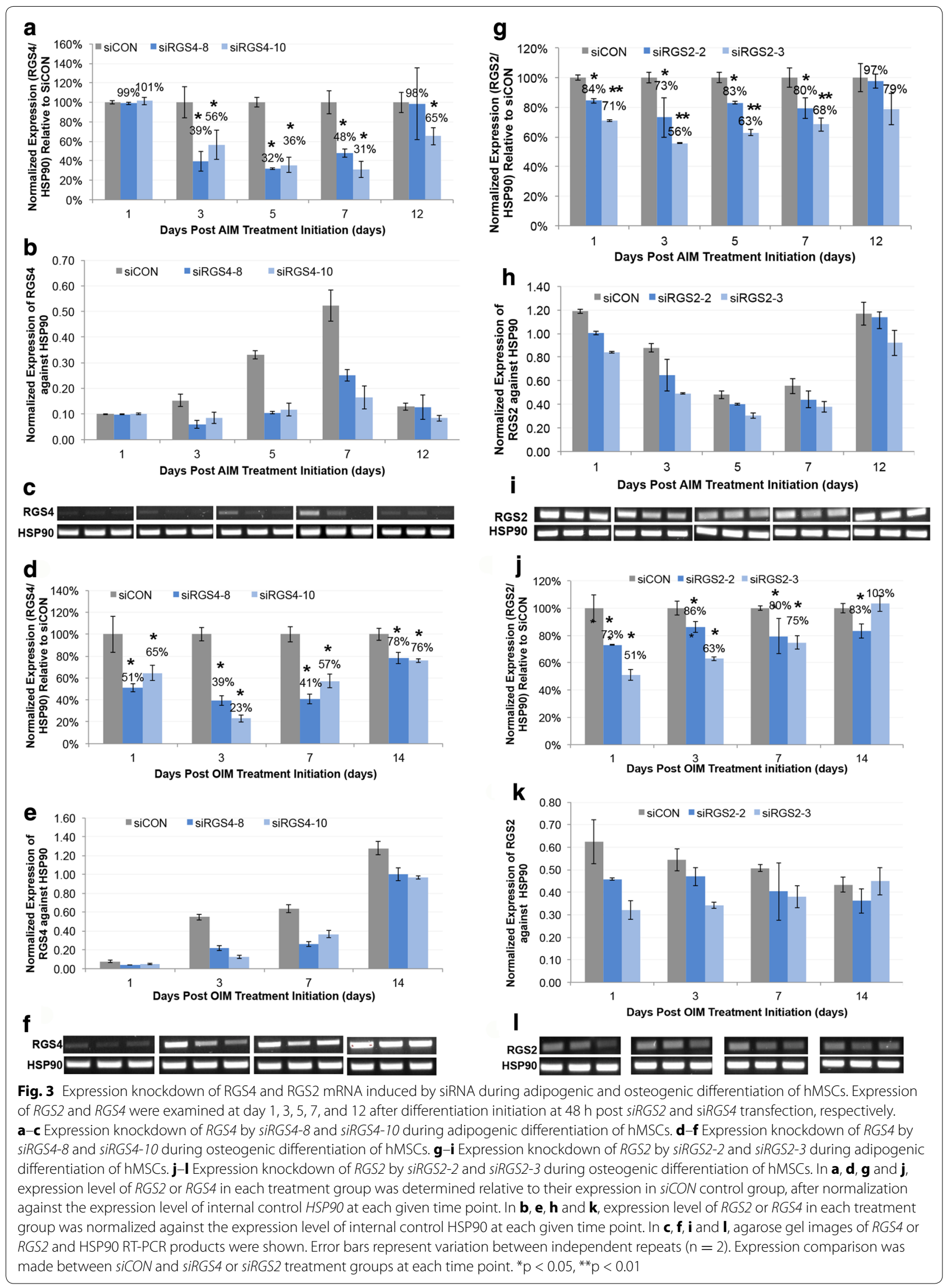


Overall, siRGS4 resulted in around 50-75\% expression knockdown in RGS4 expression at the RNA level and there was no significant difference between siRGS4-8 and siRGS4-10 in RGS4 expression knockdown at any time point tested during adipogenesis or osteogenesis.

To examine the expression knockdown of RGS4 at the protein level, western blots were carried out using two types of antibodies that recognize two different motifs of RGS4 protein separately (see "Methods"). One binds to the C-terminal sequence (amino acids 182-205) outside of the RGS domain (amino acids 62-178) and detects the RGS4 isoform 3 product at $34 \mathrm{kDa}$. The other binds to the N-terminal sequences (amino acids 40-82) and detects the RGS4 isoforms 1 and 2 both at about $23 \mathrm{kDa}$. Expression level of RGS4 was compared between siRGS48 and siRGS4-10 transfected cells and siCON transfected cells at day 1, 2, 3, 4, 5 and 7 post AIM or OIM treatment initiation. Expression level remained similar among all groups at all time points examined (data not shown), except for day 7, when expression of RGS4 isoform 3 was consistently, thought slightly, down regulated in siRGS4-8 and siRGS4-10 transfected cells as compared to in siCON transfected cells by about 30 and 20\% in AIM and OIM treatment condition, respectively (expression in OIM is shown in Additional file 5: Figure S5A). This delayed and subtle change at the protein level may imply much greater RGS4 protein stability as compared to its $R N A$ transcript, in addition to other plausible causes (see "Discussion").

In samples treated with AIM, RGS2 mRNA was significantly $(\mathrm{p}<0.05)$ lower in siRGS2-2 samples at day 1 (84\%), 3 (73\%), 5 (83\%), and 7 (80\%) compared to siCON (100\%) (Fig. 3e, f). The effect of siRGS2-2 was gone by day 12. Similarly, in siRGS2-3 treatments, $R G S 2 m R N A$ was significantly $(\mathrm{p}<0.01)$ lower at day $1(71 \%)$, and 3 (56\%), 5 (63\%), 7 (68\%) and 12 (79\%) (Fig. 3e, f). In samples treated with OIM, RGS2 $m R N A$ was significantly $(\mathrm{p}<0.05)$ lower in siRGS2-2 samples at day $1(73 \%)$, and non-significantly lower by day 3 (86\%), 7 (80\%), and 12 (83\%) (Fig. 3g, h). In siRGS2-3 samples, RGS2 mRNA was significantly $(\mathrm{p}<0.05)$ down regulated at day $1(51 \%)$, day $3(63 \%)$, day $7(75 \%)$, but resumed to control level by day 12 (103\%) (Fig. 3g, h). Overall, siRGS2-2 and siRGS2-3 resulted in expression knockdown of $R G S 2$ by $20-30$ and $30-50 \%$, respectively.

Since upregulation of RGS2 expression upon adipogenic initiation was significantly greater in Hyclone CM based AIM as compared to HI-FBS CM based AIM, and considering that the expression knockdown by siRGS2 was modest in Hyclone CM based AIM (by 20-50\%), we wondered whether siRGS2 would have greater knockdown in HI-FBS CM based AIM due to lower basal level of $R G S 2$ expression, and hence greater phenotypic effect.
Similar to previous studies, expression knockdown of RGS2 by siRGS2-2 and siRGS2-3 was evaluated at days $1,3,5,7$, and 14 post treatment initiation with HI-FBS $\mathrm{CM}$ based AIM at $48 \mathrm{~h}$ after siRNA transfection. In siRGS2-2 samples, expression of RGS2 was significantly lower (p < 0.05) at day $3(69 \%), 5(60 \%)$ and $7(51 \%)$, but resumed to control levels (97\%) at day 12 as compared to siCON samples (100\%) (Additional file 6: Figure S6). Similarly, in siRGS2-3 samples, expression of RGS2 was significantly lower ( $\mathrm{p}<0.05)$ at day $1(43 \%), 3(34 \%), 5(32 \%)$, and $7(49 \%)$ and resumed to control level by day $12(94 \%)$ compared to $s i C O N(100 \%)$ (Additional file 6: Figure S6).

Expression knockdown of RGS2 at the protein level was also examined by western blots in siRGS2-2, siRGS23 or siCON treated cells under AIM and OIM treatment conditions using Hyclone CM based media. Consistently, expression of RGS2 was down regulated by $30-40 \%$ in siRGS2-2 cells and $60-70 \%$ in siRGS2-3 cells as compared to in siCON cells on day 2 post AIM or OIM treatment initiation (expression in OIM is shown in Additional file 5: Figure S5B), which correlates well to the level of expression knockdown detected at the $R N A$ level as shown above.

In conclusion, during early adipogenic and osteogenic treatments in Hyclone CM based media, both siRGS4-8 and siRGS4-10 downregulated RGS4 expression by about $50-75 \%$ at the $R N A$ level, but only about $20-30 \%$ expression knockdown was detected in isoform 3 of RGS4 at the protein level, whereas siRGS2-2 and siRGS2-3 downregulated RGS2 expression by $20-30$ and $30-50 \%$ respectively at the RNA level and similarly by $30-40$ and $60-70 \%$ respectively at the protein level. Additionally, in HI FBS CM based AIM condition, siRGS2-3 exerted a greater level of gene silencing (by 50-70\%) compared to siRGS22 (by $30-50 \%$ ) at the $R N A$ level, both of which are greater than their respective silencing effect in Hyclone CM based AIM. Next, we examined the effect of expression knockdown induced by siRGS2 and siRGS4 on adipogenic and osteogenic differentiation of hMSCs.

\section{Expression knockdown of RGS2 and RGS4 exerts different levels of inhibitory effect on adipogenic differentiation of ad-hMSCs}

To investigate the role of RGS2 and RGS4 in adipogenesis, we measured the effect of their expression knockdown induced by siRNA on several metrics of adipogenesis. As described previously, ad-hMSCs were reverse transfected with $16.5 \mathrm{nM}$ of control $(s i C O N)$ or targeted siRNA in Hyclone growth media $(\mathrm{CM})$. After $48 \mathrm{~h}$, adipogenesis was initiated by AIM with $1.0 \mu \mathrm{M}$ DEX. After 12 days of AIM treatment, with media change at 48-h intervals, cells were fixed and stained with DAPI (nuclear stain) and OilRedO (oil droplet staining). Overlapping images 
of DAPI and OilRedO stained cells were taken from multiple wells of each treatment group for total cell counting, adipocytes counting and area measurements of stained lipid droplets in OilRedO images, and OilRedO dye was subsequently extracted with isopropanol and quantified by absorbance reading at $515 \mathrm{~nm}$ (see "Methods").

For RGS4 expression knockdown, whole-well images showed noticeably lower intensity of OilRedO stains in siRGS4-10 but not siRGS4-8 groups compared to siCON control (Fig. 4a). Correspondingly, OilRedO quantification was significantly lower in siRGS4-10 treatment group $(82 \%, \mathrm{p}<0.05)$ compared to siCON controls $(100 \%)$, and the difference between siRGS4-8 treatment group (98\%) and siCON control (100\%) was insignificant (Fig. 4b). Consistently, area measurements of stained oil droplets were significantly lower in siRGS4-10 treatment groups $(42 \%, \mathrm{p}<0.01)$ compared to $\operatorname{siCON}(100 \%)$, but insignificantly lower in RGS4-8 (85\%) compared to siCON (100\%)
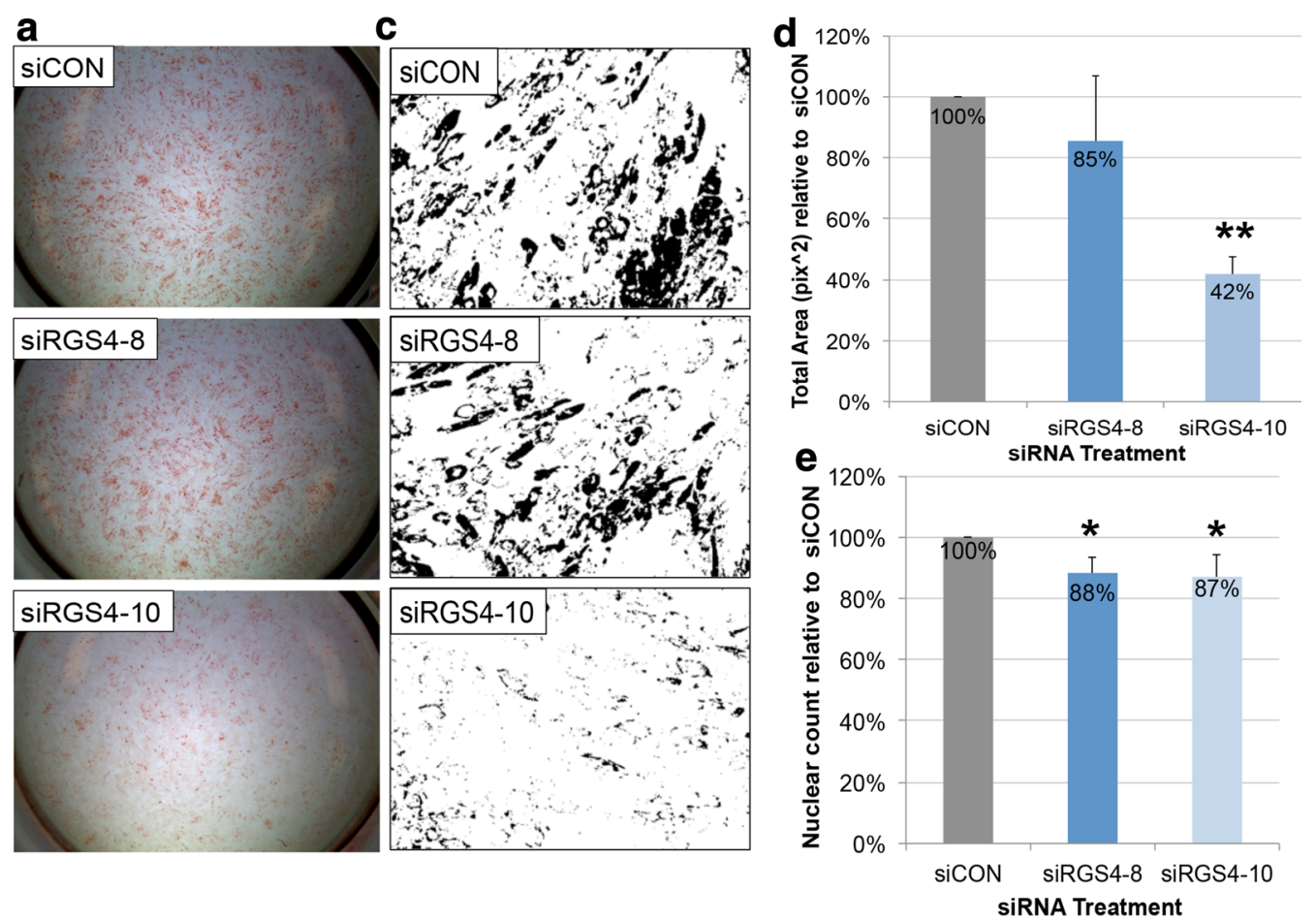
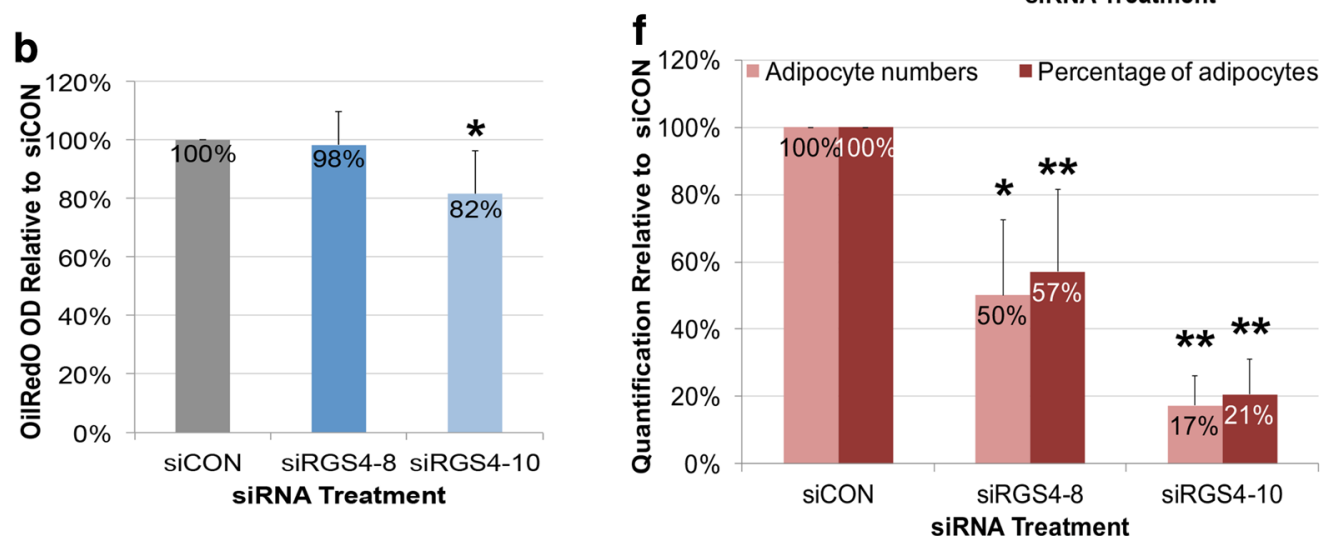

Fig. 4 Effect of siRGS4 on adipogenic differentiation of hMSCs induced by Hyclone CM based adipogenic media. a Phase contrast images of OilRedO stained wells at day 12 post adipogenic initiation. Lipid droplets were stained red. b OilRedO staining quantification by absorbance reading at $515 \mathrm{~nm}$. c Representative ImagePro area measurement images showing positively stained oil droplets in black and unstained cells in white. d Area measurement quantification of stained oil droplets. e Quantification of total nuclear count per treatment group. $\mathbf{f}$ Quantification of adipocyte count and percentage of adipocyte per treatment group. Images and graphs represent the mean quantification of siRGS4 treatment wells set relative to that of siCON treatment wells from a representative experimental $(n=3)$. Comparison was made between siCON and siRGS4 treatment groups. ${ }^{*} p<0.05,{ }^{* *} p<0.01$ 
(Fig. 4c, d). Differences in total fat accumulation could be a result of variation in adipocyte numbers and/or variation in lipid accumulation within individual adipocytes. To determine the cause, total cell counts and adipocyte cell counts were determined based on DAPI nuclear stain and manual identification of mature adipocytes in OiRedO images respectively. Total cell numbers were significantly lower in both siRGS4-8 (88\%, $\mathrm{p} \leq 0.05)$ and siRGS4-10 (87\%, $\mathrm{p} \leq 0.05)$ treatment groups compared to siCON controls (100\%) (Fig. 4e). Adipocyte cell numbers were even more drastically lower in both siRGS4-8 $(50 \%$, $\mathrm{p}<0.05)$ and RGS4-10 (17\%, $\mathrm{p}<0.01)$ treatment groups compared to siCON controls (100\%) (Fig. 4f). Percentage of adipocytes calculated by adipocytes number/total cell number was also significantly lower in siRGS4-8 (57\%, $\mathrm{p}<0.01)$ and siRGS4-10 $(21 \%, \mathrm{p}<0.01)$ treatment groups compared to siCON controls (100\%) (Fig. 4f). Overall, expression knockdown of RGS4 by siRGS4 resulted in significantly decreased total fat accumulation, total cell numbers, total adipocyte numbers and differentiation efficiency as reflected by percentage of adipocytes, with siRGS4-10 exerting greater effect than siRGS4-8.

For RGS2 expression knockdown, there was no noticeable difference in OilRedO staining intensity (Fig. 5a). OilRedO quantification was not significantly different between siRGS2-2 (99\%) or siRGS2-3 (91\%) treatment groups and siCON controls (100\%) neither (Fig. 5b). Consistently, total area $\left(\mathrm{pi}^{2}\right)$ measurements of OilRedO stained oil droplets trended lower in both siRG2-2 (81\%) and siRGS2-3 (80\%) treatment groups compared to siCON controls (100\%), but the difference was not statistically significant (Fig. 5c, d). Nuclear counts in siRGS2-2 (96\%) and siRGS2-3 (97\%) slightly but consistently trended lower than $s i C O N$ controls (100\%), though statistically insignificant neither (data not shown). Overall, siRGS2 did not significantly affect total fat areas or total cell numbers as compared to $S i C O N$ treatment in Hyclone CM based AIM condition.

The effect of siRGS2 on adipogenesis induced by HI FBS $\mathrm{CM}$ based AIM was also analyzed. In contrary to Hyclone $\mathrm{CM}$ based AIM condition, OilRedO stain intensity in both siRGS2-2 and siRGS2-3 treatments appeared visually reduced compared to siCON (Fig. 6a). Total fat accumulation quantification by OilRedO dye extraction however was only significantly lower in siRGS2-2 (86\%, p < 0.05) but not in siRGS2-3 (96\%) treatment groups as compared to siCON controls (100\%) (Fig. 6b). Consistently, total area measurements $\left(\mathrm{pi}^{2}\right)$ of stained oil droplets was significantly lower in siRGS2-2 $(55 \%, \mathrm{p}<0.05)$ and only trended lower in siRGS2-3 $(80 \%, \mathrm{p}<0.1)$ treatments as compared to in $s i C O N$ controls (100\%) (Fig. 6c, d). Subsequently we determined whether decreased total fat accumulation was the result of reduction in adipocyte numbers and/or differentiation efficiency. Total nuclear counts were only significantly lower in siRGS2-2 $(87 \%, \mathrm{p}<0.05)$ but not in siRGS2-3 (92\%) treatment groups compared to siCON controls (100\%) (Fig. 6e). Total adipocyte number trended lower in both siRGS2-2 (82\%, $\mathrm{p}<0.1)$ and siRGS2-3 $(86 \%)$ treatments compared to siCON controls (100\%) (Fig. 6f). Percent of adipocytes in siRGS2-2 (96\%) and siRGS2-3 $(90 \%)$ groups were not significantly different from $s i C O N$ controls (100\%) (Fig. 6f). Overall, in the HI FBS CM based AIM induced adipogenic differentiation, siRGS2-3 had mild inhibitory effect that was statistically deemed insignificant, but siRGS2-2 treatment significantly inhibited total fat accumulation as compared to $s i C O N$, which was likely the consequence of significantly reduced total number of cells, as differentiation efficiency determined by percentage of adipocytes was not significantly different between $s i R G S 2-2$ and $s i C O N$.

In conclusion, expression knockdown of RGS4 by 50-75\% significantly inhibited adipogenic differentiation of hMSCs by reducing total adipocytes and adipogenic differentiation efficiency, with siRGS4-10 exerting greater effect than siRGS4-8. Expression knockdown of RGS2 also exhibited similar inhibitory effect in HI-FBS CM based AIM but not Hyclone CM based AIM conditions, likely due to greater expression knockdown in the former vs. the latter, with siRGS2-2 exerting greater effect than siRGS2-3. Such effect was at least partly due to reduced total adipocytes as the result of reduced total cell numbers, without affecting differentiation efficiency.

\section{Effects of siRGS2 and siRGS4 on the expression of adipogenic markers}

Expression knockdown of RGS4 by siRGS4 resulted in significantly decreased adipogenesis in part due to reduced total cell numbers. Since differentiation efficiency as reflected by percentage of adipocytes was also reduced, it indicated that decreased adipocyte number in siRGS4 treatment groups might not be solely due to reduction in total cell number and siRGS4 might affect adipogenesis directly, resulting in decreased differentiation efficiency. On the other hand, siRGS2 had insignificant effect on adipogenesis in response to Hyclone CM based AIM but significant inhibitory effect on adipogenesis in response to HI FBS CM based AIM, without significantly affecting adipogenic differentiation efficiency. This indicated that siRGS2 did not likely affect adipogenesis directly. To test the above, the effect of $s i R G S 2$ or siRGS4 on the expression of selected adipogenic makers, PPAR , $C / E B P \alpha$ and $L P L$, was measured at day $1,3,5,7$, and 12 post adipogenic induction (Hyclone CM based AIM) in hMSCs that had been subjected to siRGS2/siRGS4 or siCON transfection. Similar to previous expression analyses, expression of those genes in siRGS2/siRGS4 treated cells was measured by RT-PCR and compared to its value 

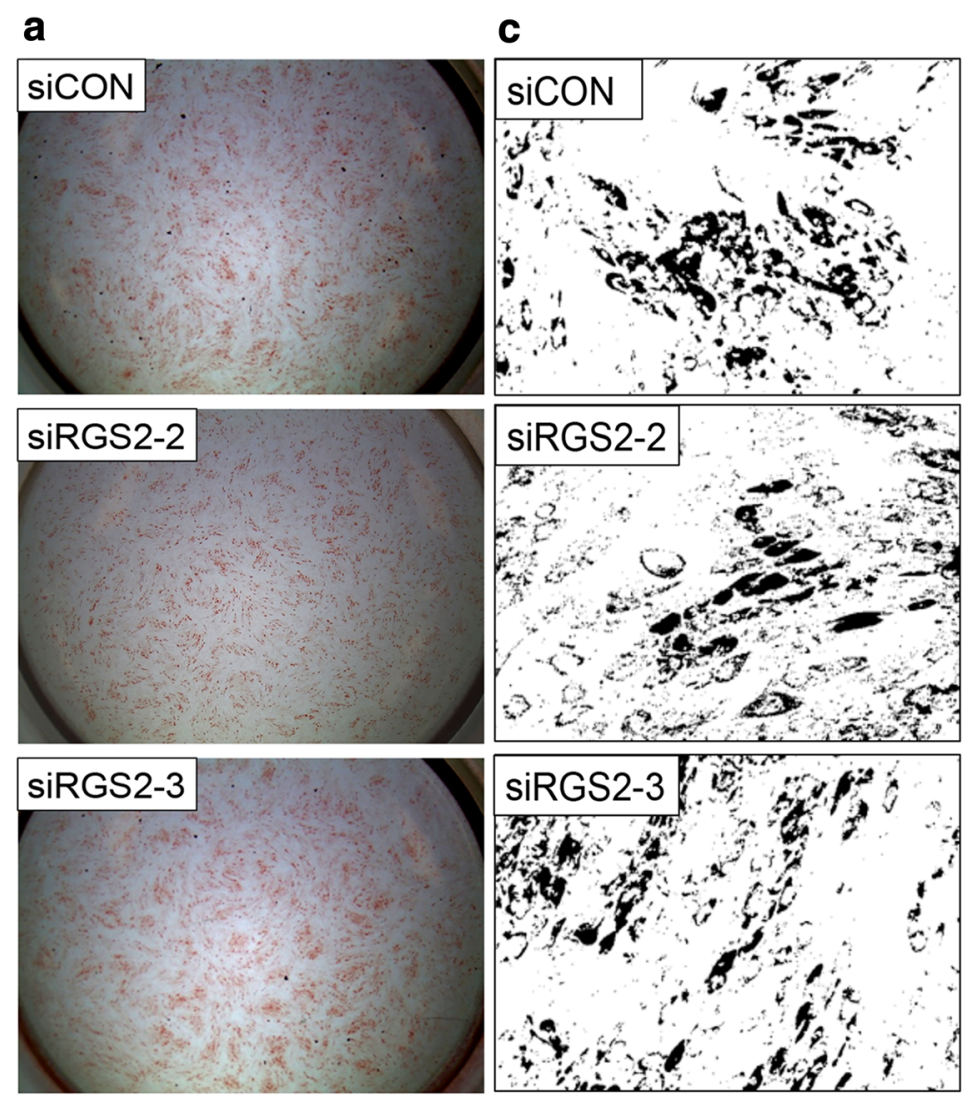

b

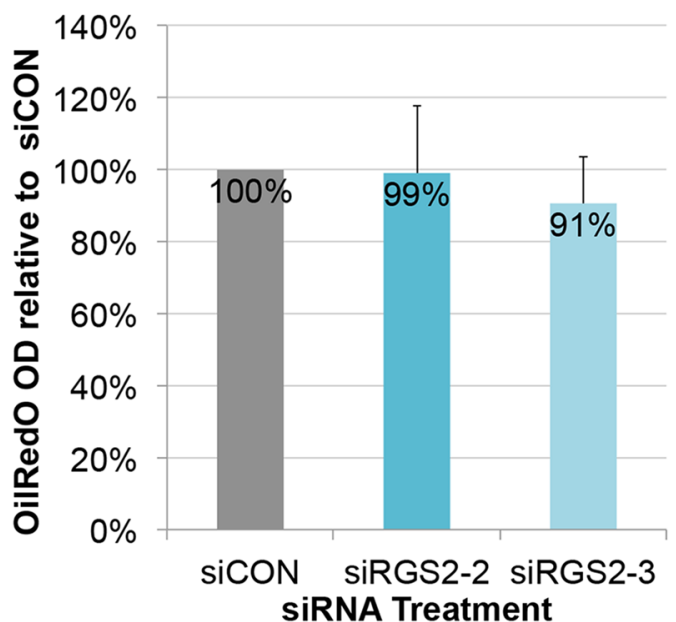

d

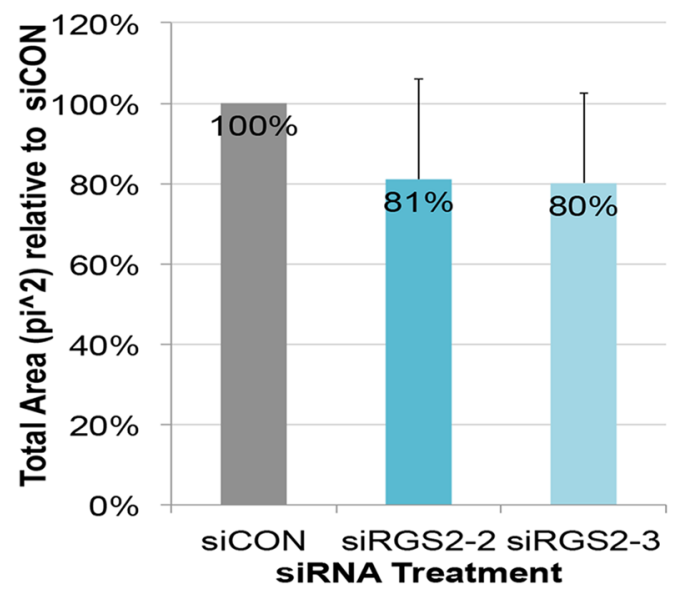

Fig. 5 Effect of siRGS2 on adipogenic differentiation of hMSCs induced by Hyclone CM based adipogenic media. a Phase contrast images of OilRedO stained wells at day 12 post adipogenic initiation. Lipid droplets were stained red. b OilRedO staining quantification by absorbance reading at $515 \mathrm{~nm}$. c Representative ImagePro area measurement images showing positively stained oil droplets in black and unstained cells in white. d Area measurement quantification of stained OilRedO oil droplets. Images and graphs represent the mean quantification of siRGS2 treatment wells set relative to that of siCON treatment wells from a representative experimental set $(n=3)$

in $\operatorname{siCON}$ treated samples at the same time point, after normalization to the expression level of internal control HSP90.
In siRGS4 samples, expression levels of PPARy and $C /$ $E B P \alpha$ in siRGS4-8 were not significantly different from siCON controls at all time points examined, except for 

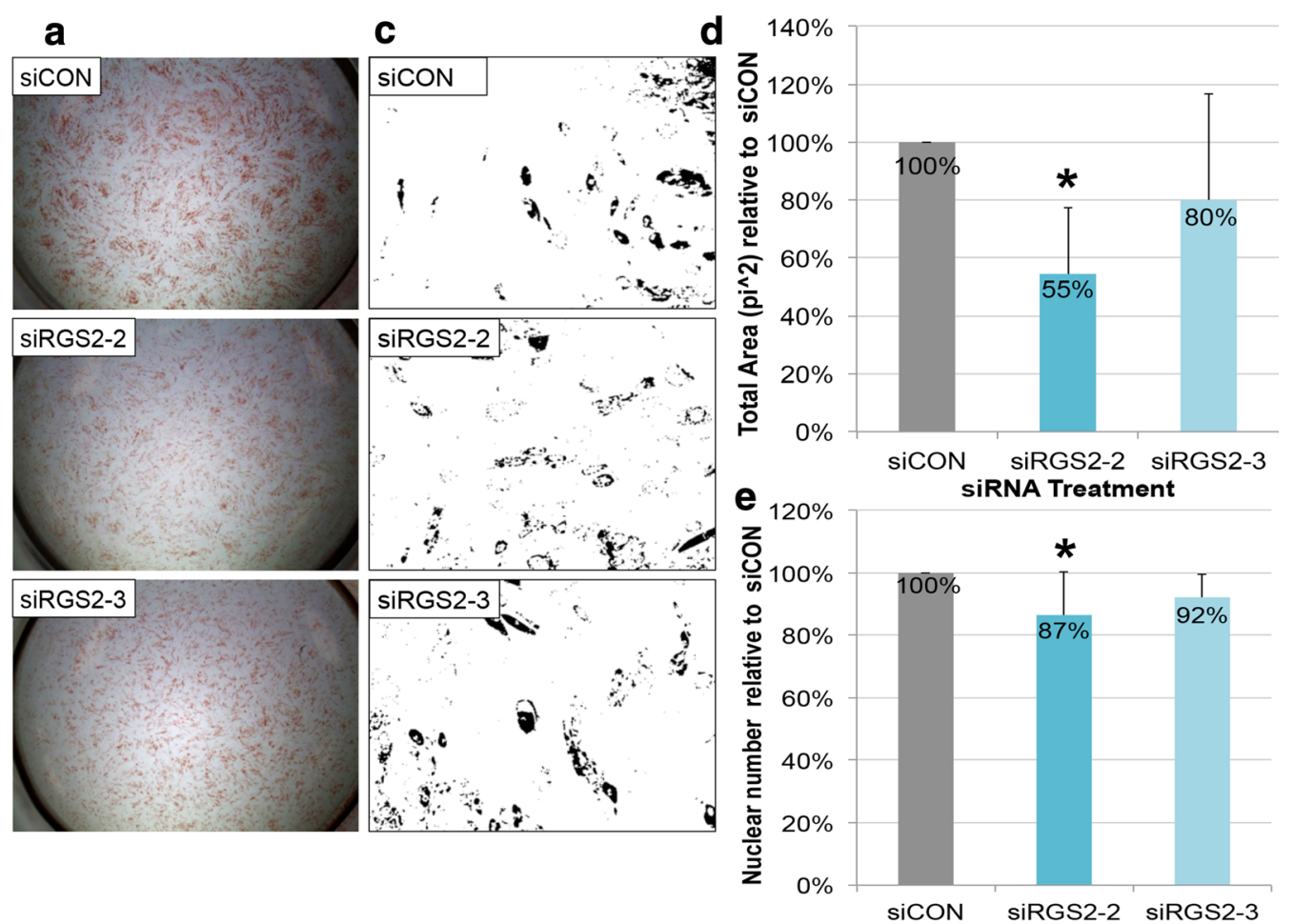

b

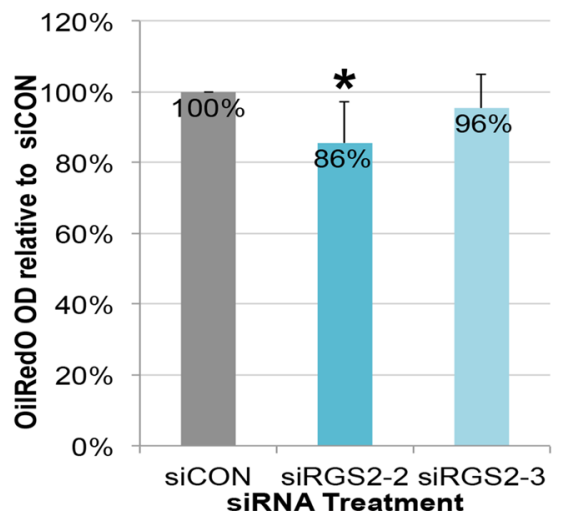

f

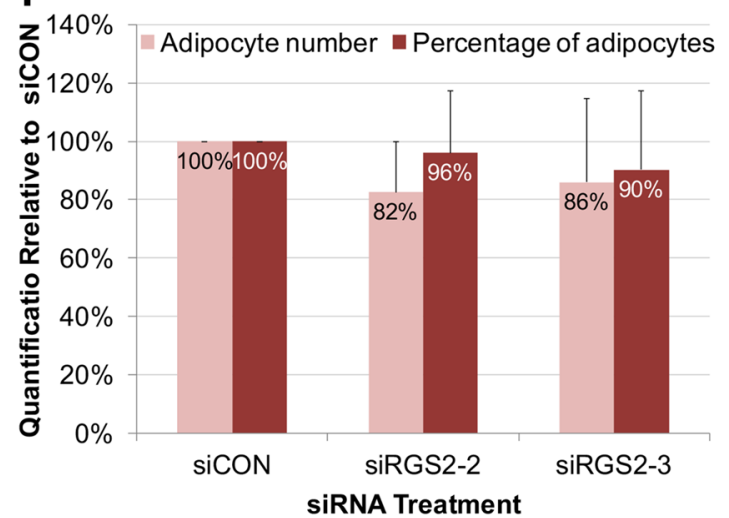

Fig. 6 Effect of siRGS2 on adipogenic differentiation of hMSCs induced by HI-FBS CM based AIM. Ad-hMSCs were transfected 2 days prior to differentiation induction with HI-FBS CM based AIM media. a Phase contrast images of OilRedO stained wells at day 12 post adipogenic initiation. Lipid droplets were stained red. b OilRedO staining quantification by absorbance reading at $515 \mathrm{~nm}$. c Representative ImagePro area measurement images showing positively stained oil droplets in black and unstained cells in white. $\mathbf{d}$ Area measurement quantification of stained oil droplets. $\mathbf{e}$ Total cell count based on DAPI nuclear stain. f Adipocytes cell count and percentage of adipocytes. Images and graphs represent the mean quantification of siRGS4 treatment wells set relative to that of siCON wells from a representative experimental set $(n=3)$. Comparison was made between siCON and siRGS2 treatment groups. ${ }^{*} p<0.05$

PPAR upregulation at day $1(130 \%, \mathrm{p}<0.05)$ and $C /$ $E B P \alpha$ downregulation at day $12(20 \%, \mathrm{p}<0.05)$ compared to $\operatorname{siCON}(100 \%)$ (Fig. 7a, b). However, in siRGS4-10 samples PPARY expression level overall trended lower while $C / E B P \alpha$ was significantly down regulated at all time points $(15-25 \%, \mathrm{p}<0.05)$ compared to siCON controls (100\%) (Fig. 7a, b). Expression of LPL on the other hand was significantly down regulated in both siRGS4-8 and siRGS4-10, with $45 \%$ at day $5,77 \%$ at day 7 and $23 \%$ at day 12 in the former and $18 \%$ at day $3,33 \%$ at day $5,22 \%$ at day 7 and $6 \%$ at day 12 in the latter samples as compared to siCON (100\%) (Fig. 7c). Overall, expression of both $C / E B P \alpha$ and $L P L$ were significantly down regulated by siRGS4-10 at multiple time points during adipogenic 

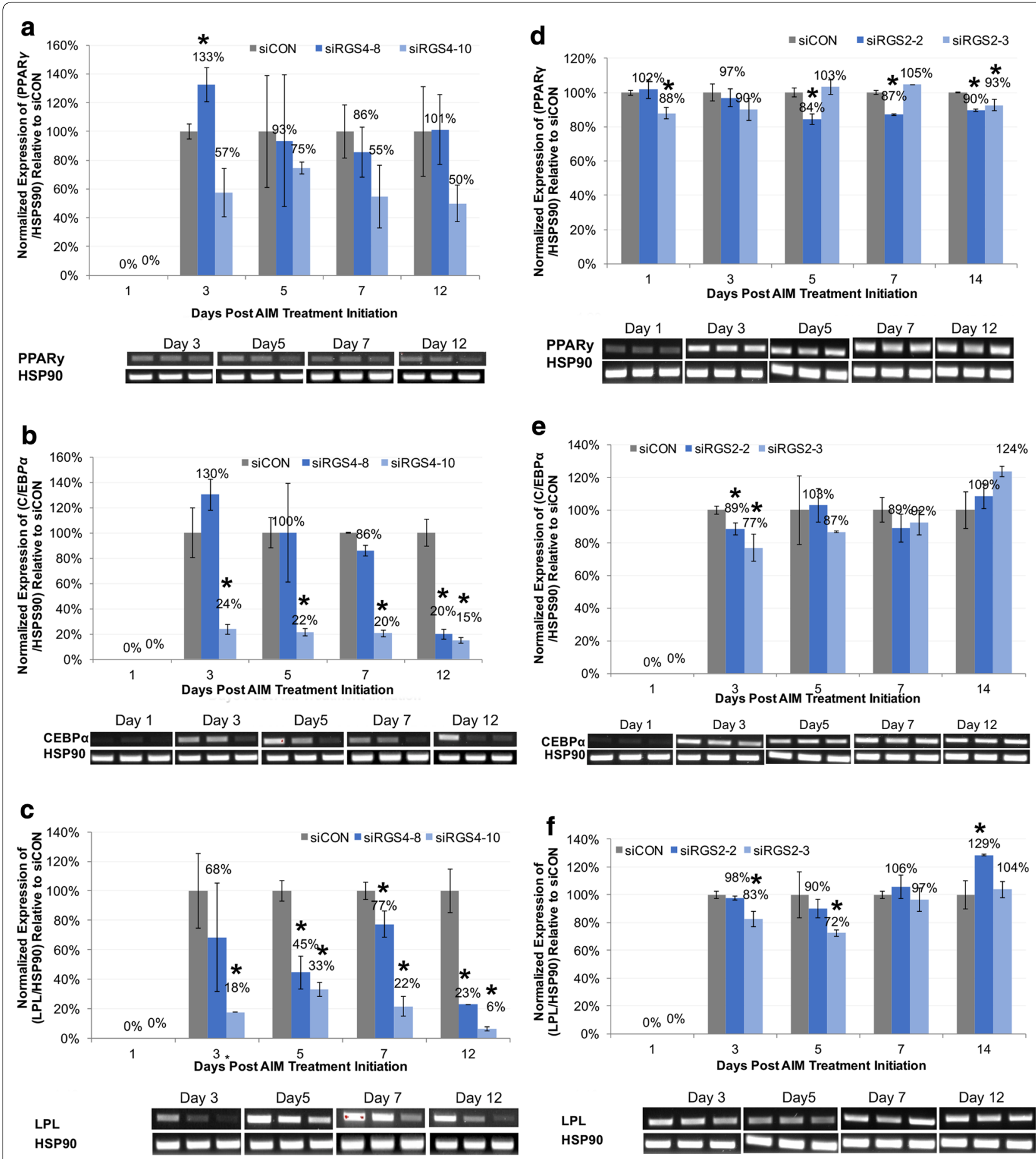

LPL

HSP90

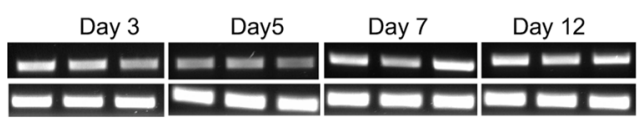

Fig. 7 Effect of siRGS4 and siRGS2 on the expression of adipogenic markers during adipogenic differentiation of hMSCs induced by Hyclone CM based adipogenic media. Expression of PPARY, C/EBPa and LPL were examined at day 1, 3, 5, 7 and 12 post adipogenic treatment initiation in siCON and siRGS4 (a-c) or siRGS2 (d-f) transfected AD-hMSCs. Graphs represent average expression level of each gene normalized to that of HSP90 and set relative to its normalized expression in siCON transfected cells. Agarose gels show RT-PCR products of examined genes and HSP90 at indicated time points. a Expression of PPARY in siRGS4 and siCON transfected cells. b Expression of C/EBPa in siRGS4 and siCON transfected cells. c Expression of LPL in siRGS4 and siCON transfected cells. d Expression of PPARY in siRGS2 and siCON transfected cells. e Expression of C/EBPa in siRGS2 and siCON transfected cells. $\mathbf{f}$ Expression of $L P L$ in siRGS2 and siCON transfected cells. Error bars represent variation between independent repeats $(n=2)$. Expression comparison was made between siCON and siRGS2 or siRGS4 treatment groups at each given time point. ${ }^{*} p<0.05,{ }^{* *} p<0.01$ 
differentiation, whereas only $L P L$ was down regulated

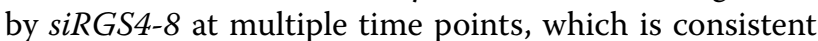
with the more disruptive effect of siRGS4-10 on adipogenic differentiation of hMSCs as compared to siRGS4-8.

In siRGS2 samples, expression level of PPARy was slightly but significantly lower in siRGS2-2 treatments (84-90\%) as compared to $\operatorname{siCON}(100 \%)$ on day 5,7 and 12 , and similar difference between siRGS2-3 and siCON was observed on day 1 and day 12 (Fig. 7e). Expression of $C / E B P \alpha$ was also slightly but significantly downregulated by $\operatorname{siRGS2-2}(89 \%)$ and siRGS2-3 (77\%) on day 3 compared to $\operatorname{siCON}(100 \%)$, but remained unchanged at the other time points (Fig. 7f). Expression of $L P L$ was upregulated in siRGS2-2 samples at day $12(129 \%, \mathrm{p}<0.05)$ compared to siCON controls (100\%), but was not significantly changed at the other time points. In siRGS2-3 samples, levels of $L P L$ were slightly but significantly lower at day $3(83 \%)$ and $5(72 \%)$ compared to siCON samples (100\%), but remained insignificantly different at the other time points (Fig. 7g). Overall, both siRGS2-2 and siRGS23 had a subtle suppressive effect on the expression of both $P P A R \gamma$ and $C / E B P \alpha$, and only siRGS2-3 appeared to have a subtle suppressive effect on the expression of $L P L$, consistent with the overall mild and insignificant effect of siRGS2 on total fat accumulation in Hyclone CM based AIM condition.

Since siRGS2 exerted significant inhibitory effect on adipogenic differentiation of hMSCs induced by HI-FBS CM based AIM, expression of all four adipogenic marker genes was also examined in such condition. Expression of PPARY was slightly but significantly down regulated by $\operatorname{siRGS2-2}$ at day $3(76 \%, \mathrm{p}<0.05)$ and day $5(88 \%$, $\mathrm{p}<0.05)$ but not by siRGS2-3 as compared to siCON (100\%) (Fig. 8a). C/EBP $\alpha$ expression on the other hand was upregulated in siRGS2-2 treatment groups at day $7(120 \%, \mathrm{p}<0.05)$ and $12(160 \%, \mathrm{p}<0.05)$, but slightly downregulated in siRGS2-3 at day 3 (73\%, p < 0.05) compared to siCON (100\%) (Fig. 8b). LPL expression was only downregulated by siRGS2-2 $(50 \%, \mathrm{p}<0.05)$ at day 5 but not by siRGS2-3 compared to siCON (100\%) (Fig. 8c). Overall, siRGS2-2 slightly down regulated expression of PPAR $\gamma$ and $L P L$, but upregulated $C / E B P \alpha$, whereas $\operatorname{siRGS2-3}$ had minimum effect on the expression of these genes except for transient downregulation of $C / E B P \alpha$. This is consistent with previous observation that compared to $s i R G S 2-3$, siRGS2-2 exerted greater inhibitory effect on adipogenesis induced by HI FBS CM based AIM. In addition, effect of siRGS2-2 on adipogenic gene expression was only slight, consistent with previous observation that siRGS2-2 did not significantly affect differentiation efficiency determined by percentage of adipocytes, and its inhibitory effect on adipogenesis was mainly likely due to reduced adipocytes as the result of

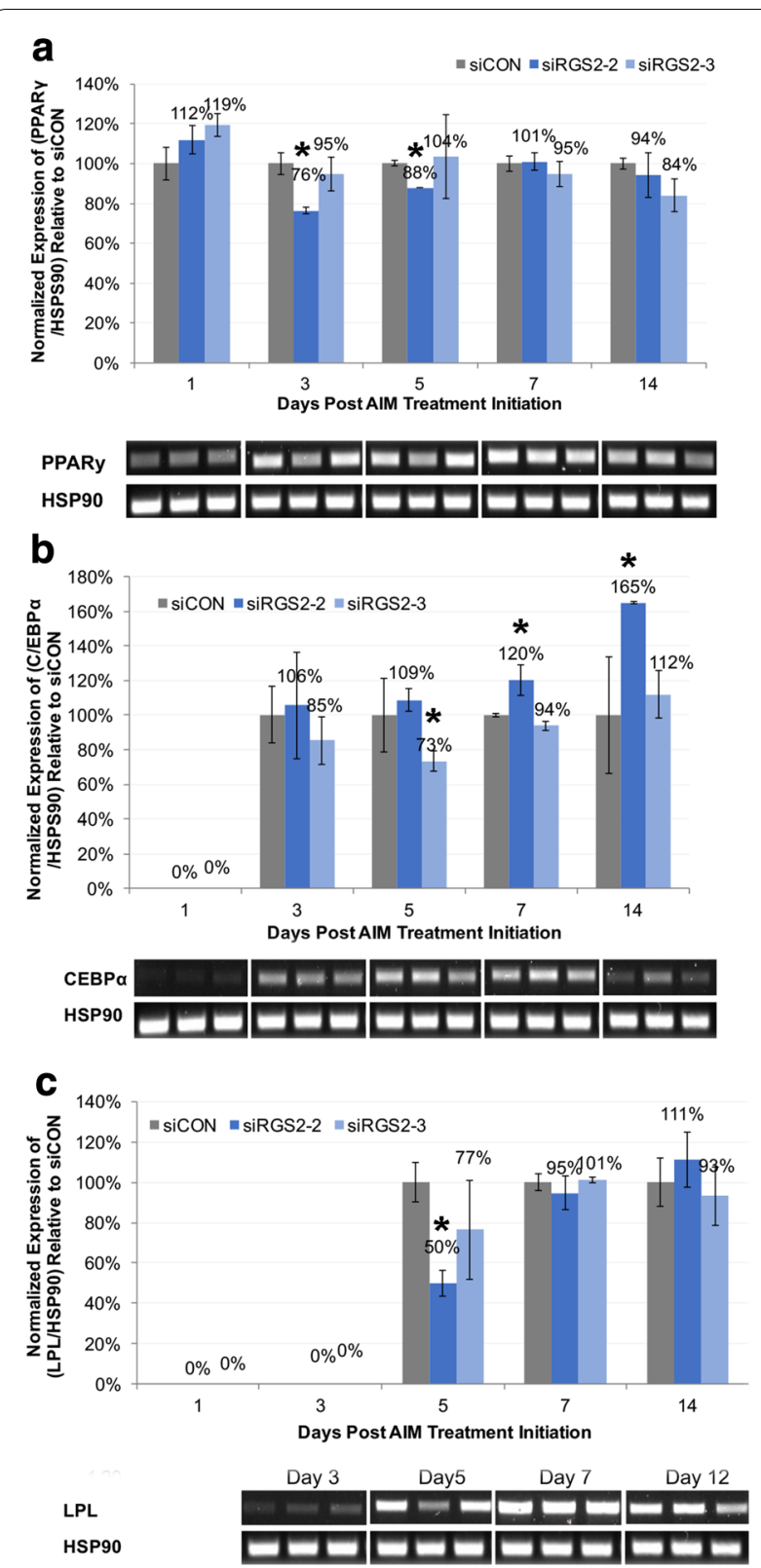

Fig. 8 Effect of siRGS2 on the expression of adipogenic markers during adipogenic differentiation of hMSCs induced by HI FBS CM based adipogenic media. Expression of PPARY, C/EBPa and $L P L$ were examined at day 1, 3, 5, 7 and 12 post adipogenic treatment initiation in siCON and siRGS2 transfected AD-hMSCs. Graphs represent average expression level of each gene normalized to that of HSP9O and set relative to its normalized expression in siCON transfected cells. Agarose gels show RT-PCR products of examined genes and HSP9O at indicated time points. a Expression of PPARY in siRGS2 and siCON transfected cells. b Expression of C/EBPa in siRG2 and siCON transfected cells. c Expression of LPL in siRGS2 and siCON transfected cells. Error bars represent variation between independent repeats $(n=2)$. Expression comparison was made between siCON and siRGS2 or siRGS4 treatment groups at each given time point. ${ }^{*} p<0.05$ 
reduced total cell numbers and possibly reduced fat accumulation per adipocyte as well.

In conclusion, consistent with their different levels of inhibitory effect on the adipogenic outcome of hMSCs, siRGS4 exerted significantly greater level of inhibition on the expression of adipogenic marker genes (PPAR $C / E B P \alpha$, and $L P L)$ than siRGS2. In addition, siRGS4-10 downregulated all three genes whereas siRGS4-8 only inhibited $L P L$, which is also consistent with the more disruptive effect of siRGS4-10 on adipogenic differentiation of hMSCs as compared to siRGS4-8.

\section{Effect of siRGS2 and siRGS4 in osteogenic differentiation of hMSCs}

To investigate the potential role of RGS2 and RGS4 during osteogenic differentiation of hMSCs, we applied the same D-2/D0 siRNA transfection approach. Briefly, even number of ad-hMSCs were reverse transfected with xtremeGENE/siRNA complex at $16.5 \mathrm{nM}$ in Hyclone control (CM) media. After $48 \mathrm{~h}$, osteogenesis was induced by $0.2 \mu \mathrm{M}$ DEX OIM media, which was subsequently changed every $48 \mathrm{~h}$. After 18-26 days of OIM media treatment, cells were fixed and stained with alizarin red S, which specifically stains for calcific deposit (hydroxylapatite) by osteocytes. Alizarin Red S dye was subsequently extracted with acetic acid and quantified calorimetrically at $405 \mathrm{~nm}$ as a measurement of osteogenic differentiation efficiency (see "Methods").

In comparison to $s i C O N$ treatments, there was increased as well as earlier onset of calcific deposit (day 11) present in siRGS4-10 treatment groups but not so much in siRGS4-8 groups (Fig. 9a, top row), which could also be visually confirmed by increased amount of Alizarin Red S stain in siRGS4-10 treatment groups at the end of differentiation (day 18-24) (Fig. 9a, middle row). On the other hand, mineral deposit was decreased in both siRGS2-2 and siRGS2-3 samples compared to siCON groups (Fig. 9a, bottom row). Consistently, Alizarin Red S quantification was significantly higher in siRGS410 treated samples $(169 \%, \mathrm{p}<0.05)$ (Fig. 9b), but significantly lower in both siRGS2-2 (84\%, p < 0.05) and siRGS2-3 $(68 \%, \mathrm{p}<0.05)$ treated samples compared to siCON controls (100\%) (Fig. 9c). Nuclear count revealed no significant difference between siCON and any siRGS4 or siRGS2 treatment groups (data not shown).

In conclusion, siRGS4 and siRGS2 had opposing effect on osteogenic differentiation of hMSCs, with the former promoting while the latter inhibiting the process, without affecting total cell numbers. In addition, similar to a more disruptive effect of siRGS4-10 on adipogenic differentiation of hMSCs as compared to siRGS4-8, the former also demonstrated a greater enhancing effect on osteogenic differentiation of hMSCs compared to the latter.

\section{Effects of siRGS2 and siRGS4 on the expression of osteogenic markers}

Since siRGS4 promoted osteogenic differentiation of hMSCs while siRGS2 inhibited it without affecting total cell numbers, it implied a direct effect on osteogenic differentiation. Effect of siRGS4 and siRGS2 on the temporal expression of known osteogenic markers, Runx2, Osteocalcin (OC) and alkaline phosphatase (ALP) was further evaluated. Runx2 is an osteogenic master regulator [14]. $O C$ encodes a bone specific protein synthesized by osteoblast and serves as a marker of osteogenic maturation [59], while $A L P$ encodes an enzyme that function to promote mineralization by increasing phosphate concentrations $[60,61]$. Since type II/p57 isoform of Runx2 has been shown to be bone specific [62], primers amplifying specifically the $\mathrm{N}$-terminal region of the gene that encodes the bone-specific MASNS polypeptide domain was used in analyzing the expression of Runx2.

In siRGS4 OIM treatments, Runx2 expression was upregulated in both siRGS4-8 and siRGS4-10 treated cells as compared to siCON controls starting on D3 post OIM treatment initiation, but the enhancement is clearly much stronger in siRGS4-10 samples, at about 2- to 4-fold higher level than in siRGS4-8 (Fig. 10a), which is consistent with the greater effect of siRGS4-10 on promoting osteogenic differentiation. For expression of OC, no significant difference between siCON and siRGS4-8 or siRGS4-10 samples was observed at any time point analyzed (Fig. 10b). Expression of $A L P$ was also very similar between siRGS48/siRGS4-10 and siCON at all time points, except for day 7, when it was slightly down regulated in siRGS4-8 (84\%, $\mathrm{p}<0.05$ ) (Fig. 10c). Overall, Runx2 was upregulated by both siRGS4-8 and siRGS4-10, but at much greater level by the latter. $A L P$ appeared to be transiently downregulated by siRGS4-8 but remained unaffected by siRGS4-10.

In $\operatorname{siRGS2}$ OIM treatments, Runx2 was down regulated by both $s i R G S 2-2$ and $s i R G S 2-3$ treatment starting at day 1 and lasted at least until day 7 , at about $52-88 \%$ expression level of its normal expression $(\mathrm{p}<0.05)$ in siCON (100\%) (Fig. 10d). Expression of $O C$ in siRGS2-2 and siRGS2-3 did not significantly differ from siCON treatment at day 1 , but was transiently upregulated at day 3 $(146 \%, \mathrm{p}<0.05)$ and day $5(120 \%, \mathrm{p}<0.05)$ in siRGS2-2 and at day $14(124 \%, \mathrm{p}<0.05)$ in siRGS2-3 compared to siCON (100\%) (Fig. 10e). Finally, expression of $A L P$ was slightly downregulated in siRGS2-2 (84\%) and siRGS2$3(87 \%)$ but then was transiently upregulated at day 3 $(124 \%, \mathrm{p}<0.05)$ and day $5(122 \%, \mathrm{p}<0.05)$ in siRGS22 and at day $14(127 \%, \mathrm{p}<0.05)$ in siRGS2-3 compared to $\operatorname{siCON}$ (100\%) (Fig. 10f). Overall, Runx2 was slightly downregulated by both siRGS2-2 and siRGS2-3 from day 1 until at least day 7. ALP expression was also detected to be slightly downregulated on day 1 , but was shifted to 


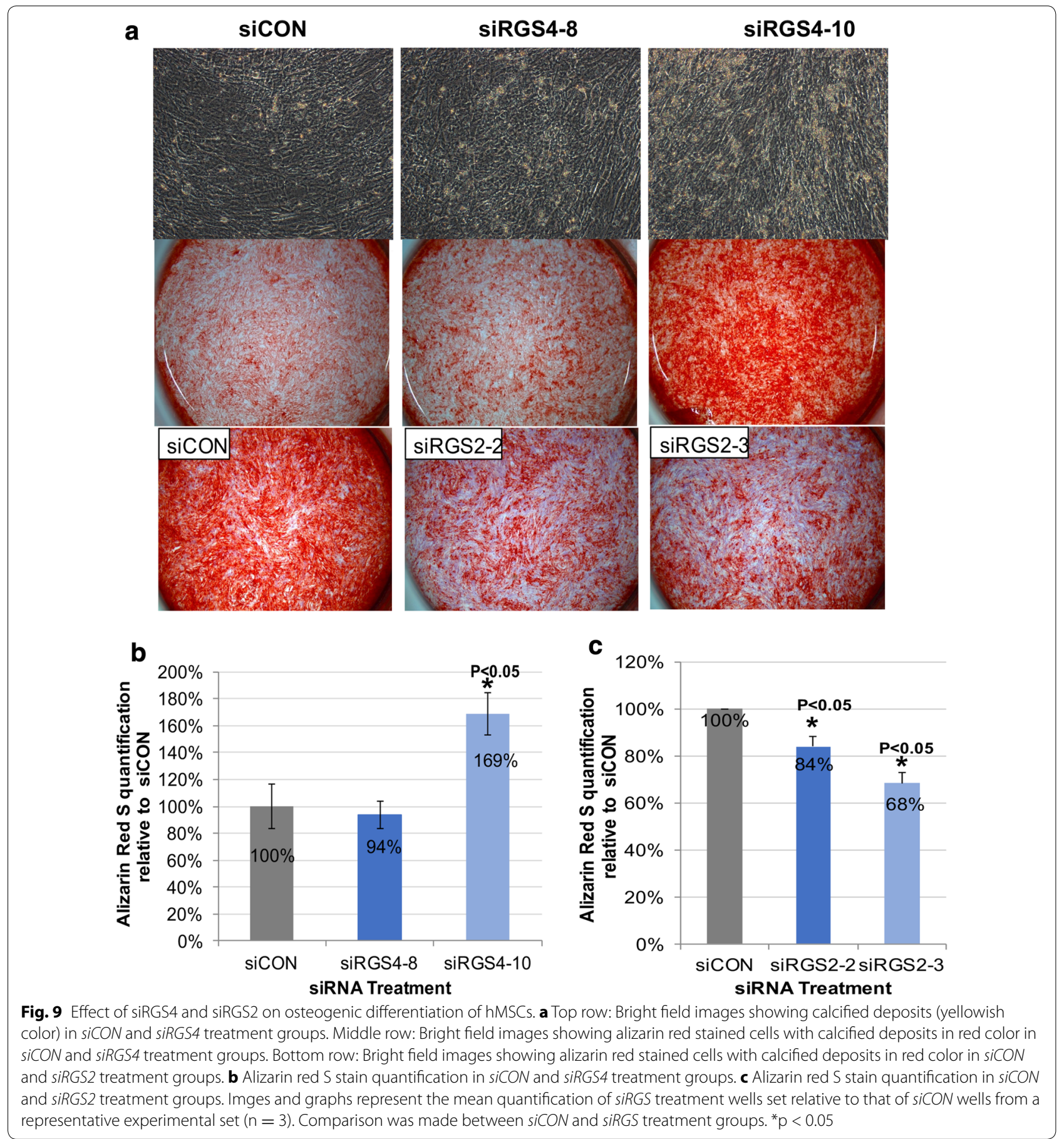

slight upregulation on later days. Expression of $O C$ was also slightly upregulated by siRGS2-2 or siRGS2-3 at day 3 and 7 or day 14 , respectively, following the same trend as $A L P$ expression on those days.

In conclusion, Runx2 was upregulated by both siRGS48 and siRGS4-10 throughout osteogenic differentiation but downregulated by siRGS2-2 and siRGS2-3. RGS4 silencing had no significant effect on the expression of
$O C$ or $A L P$, while $R G S 2$ silencing transiently downregulated $A L P$ expression early on before upregulating it along with $O C$ at later time points.

\section{Discussion}

To the best of our knowledge, this is the first study analyzing the expression regulation and function of RGS proteins during human adipogenesis and osteogenesis by 

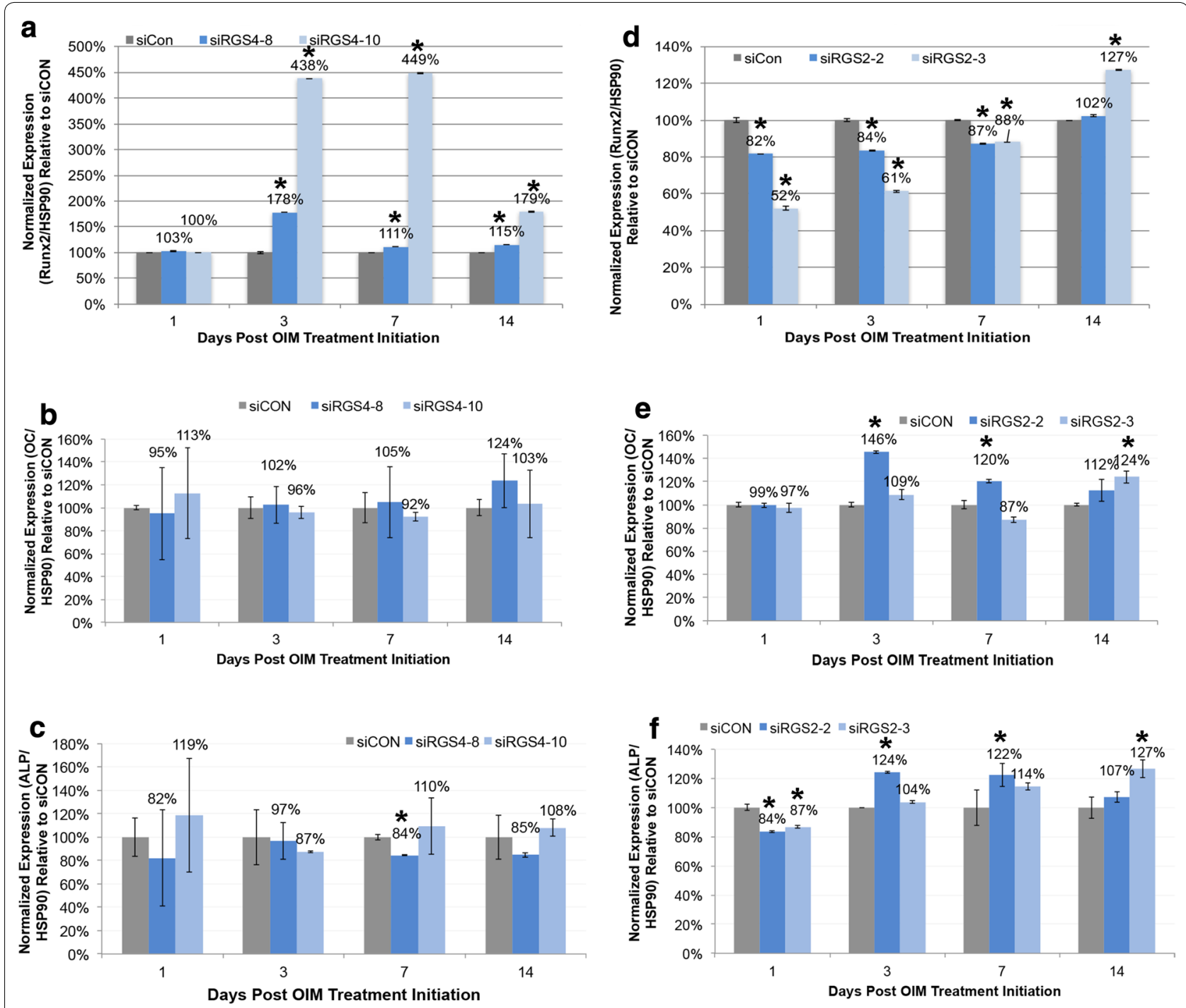

Fig. 10 Effect of siRGS4 and siRGS2 on the expression of osteogenic markers. Expression of Runx2, OC and ALP were examined at day 1,3,7 and 14 post osteogenic treatment initiation in siCON and siRGS4 (a-c) or siRGS2 (d-f) transfected AD-hMSCs. Graphs represent average expression level of each gene normalized to that of HSP90 and set relative to its normalized expression in siCON transfected cells. a Expression of Runx2 in siRGS4 and siCON transfected cells. b Expression of OC in siRGS4 and siCON transfected cells. c Expression of ALP in siRGS4 and siCON transfected cells. d Expression of Runx2 in siRGS2 and siCON transfected cells. e Expression of OC in siRGS2 and siCON transfected cells. $\mathbf{f}$ Expression of ALP in siRGS2 and siCON transfected cells. Error bars represent variation between independent repeats $(n=2)$. Expression comparison was made between siCON and siRGS treatment groups at each given time point. ${ }^{*} p<0.05$

using hMSCs as an in vitro cellular model. RGS protein family contains over twenty members categorized into four subfamilies (R4/B, RZ/A, R7/C, and R12/D). Both RGS2 and RGS4 belong to the R4/B subfamily, along with RGS1, 3, 5, 8, 13, 16, 18 and 21 [63]. RGS proteins are intracellular proteins possessing GTPase activating protein (GAP) activity, which stimulates GTP hydrolysis of $G \alpha$ subunit, leading to its re-association with the $G \beta \gamma$ of $\mathrm{G}$ proteins and termination of GPCR mediated signaling [37]. Both the $G \alpha$ and the $G \beta \gamma$ dimer can go on to activate downstream effectors like adenylyl cyclase, phospholipase $C$ (PLC- $\beta$ ), RhoA signaling, and ion channels $[64,65]$. The duration of an activated GPCR-G protein is defined by the time that the Go subunit is in its GTPbound state [66], hence is regulated by the activities of RGS proteins. Go subunits are subdivided into four subgroups based on sequence homology and effector selectivity: $\mathrm{G \alpha}_{\mathrm{s}}, \mathrm{G \alpha}_{\mathrm{i} / \mathrm{o}}, \mathrm{G \alpha}_{\mathrm{q}}, \mathrm{G \alpha}_{12}$ [67]. These $\mathrm{G \alpha}$ members can either activate or inactivate distinct downstream effectors and its selectivity of RGS proteins is dependent on 
sequence elements within and outside the RGS domain and the helical domain of $G \alpha$ proteins $[68,69]$. RGS2 possesses intrinsic GAP activity that is selective for $\mathrm{G}_{\mathrm{q}}$-class Go subunits, whereas RGS4 has intrinsic GAP activity for both $G_{q}$ and $G_{i / o}$-class $G \alpha$ subunits [38, 39]. However, it is poorly understood as to how the specificity of RGS/GPCR coupling is achieved and how different RGS proteins might coordinate with each other in regulating the same biological events. Our study revealed an interestingly opposite gene expression pattern of RGS2 and RGS4 in response to adipogenic induction, which initially triggered our interest in further understanding their roles during human adipogenesis.

RGS4 was expressed in high level in hMSCs but was quickly down regulated to near undetectable level within $24 \mathrm{~h}$ post adipogenic initiation. Expression knockdown of RGS4 by siRGS4 resulted in significantly reduced total cell numbers, indicating that it normally plays a role in regulating cell proliferation, and possibly a role in hMSCs self-renewal. Interestingly, down regulation of RGS4 also inhibited adipogenic differentiation of hMSCs, indicating that it plays a positive role during adipogenesis, which seems to contradict with its down regulation in response to adipogenic induction. One could speculate that its down regulation during the first 3 days of adipogenic induction might be necessary for hMSCs to exit its 'stem cell' mode and prepare for differentiation, however, subsequent adipogenic commitment (day 3 and day 6 post adipogenic initiation) and maturation (after day 6) would benefit from up-regulation of RGS4 expression. Molecular study indeed demonstrated that siRGS4 inhibited the expression of PPARY and C/EBP $\alpha$, whose normal upregulation in response to adipogenic induction is concomitant with the onset of adipogenic commitment, suggesting that RGS4 expression is beneficial to the upregulation of those two master control genes. It is also possible that the down regulation of RGS4 during normal adipogenic differentiation of hMSCs might have exerted a negative effect throughout and maintaining its high level of expression as in undifferentiated hMSCs could have significantly facilitated the differentiation process. To distinguish the two different scenarios would require additional future study to effectively overexpress RGS4 during adipogenic differentiation. Nevertheless, our observation of the positive role that RGS4 plays during adipogenesis is consistent with past study of RGS4 knockout mice, which showed a significantly lower body weight compared to wild type mice [53], though in a separate study, the observed weight difference was contributed to increased catecholamine secretion in adrenal gland and consequently lipolysis in adipose tissue [54].

On the other hand, expression of RGS2 was very low in hMSCs but escalated to high level within $24 \mathrm{~h}$ of adipogenic initiation, which lasted until day 6 post adipogenic initiation before subsiding to the same expression level as in hMSCs. Our functional study of RGS2 also demonstrated that it normally played a positive role during adipogenic differentiation of hMSCs, as its expression knockdown led to decreased differentiation. However, unlike RGS4, knockdown of RGS2 did not appear to exert significant effect on the expression of known adipogenic marker genes including PPAR,$C / E B P \alpha$ and $L P L$, suggesting that RGS2 might normally regulate adipogenesis through a different route. Nevertheless, the overall effect of siRGS2 on adipogenesis is consistent with past findings from RGS2 knockout mice, which have lower weights, reduced fat deposits, decreased serum lipids, and lower leptin levels $[50,51]$. It is interesting to note that there was greater phenotypic suppression on adipogenesis by siRGS2 in HI FBS CM based AIM compared to Hyclone CM based AIM, which corresponded to a greater level of RGS2 expression knockdown by siRGS2 in the former vs. the latter condition. It is possible that expression knockdown is context dependent and may be more effective when the target gene's overall expression level is lower.

While future studies are needed to understand the molecular mechanisms by which RGS2 and RGS4 might regulate adipogenesis, one could hypothesize a couple of potential mechanisms. Both $\mathrm{G}_{\mathrm{q}}$ - and $\mathrm{G}_{\mathrm{i}}$-class $\mathrm{G \alpha}$ proteins can activate Rho (a subfamily of small GTPase proteins including RhoA) regulated signaling pathways involved in cytoskeletal remodeling, cell movement and organelle development [70-72]. RhoA-ROCK signaling plays important role in adipogenic commitment and ROCK inhibitor promotes adipogenesis [71]. Induction of adipogenic differentiation leads to disruption of actin stress fibres through downregulation of RhoA-ROCK signaling and increased monomeric G-actin and its association with MKL1, a transcriptional coactivator, which prevents the nuclear localization of MKL1 and allows subsequent expression of PPAR $\gamma$ [73]. It is plausible that attenuation of $G_{\alpha i}$ and/or $G_{\alpha q}$ activity by RGS4 or RGS2 is important for downregulating RhoA-ROCK signaling and allowing subsequent activation of PPAR $\gamma$. Additionally, $\mathrm{G}_{\mathrm{i}}$-class $\mathrm{G} \alpha$ proteins can inhibit adenylyl cyclase (AC) activity required for cAMP production. Increased cAMP level as the result of IBMX induction plays a key role in adipogenic commitment [17, 74]. By inactivating $G_{\alpha i}$, it is conceivable that RGS4 may allow the activation of $\mathrm{AC}$ and subsequent intracellular increase of cAMP to promote adipogenesis.

In addition, few past studies investigated the role of RGS proteins in osteogenesis. Bone remodeling involves bone reabsorption mediated by osteoclasts and bone production mediated by osteocytes. Several past studies have suggested a role of RGS proteins in bone remodeling. For example, RGS18 promotes osteoclastogenesis whereas 
RGS12 and RGS10 impairs it [48, 75, 76]. However no study thus far has examined the role of RGS in osteogenesis, though several GPCRs like parathyroid hormone 1 receptor (PTH1R), frizzled (Fz), and calcium sensing receptor (CaSR), which play important roles in osteoblast differentiation and function, are expressed in osteoblast and regulated by RGS proteins [49]. Activated PTH1R triggers the activation of $G_{\alpha q}-P L C$ and $G_{\alpha s}-A C$ signaling $[77,78] . \mathrm{G}_{\mathrm{q}}$-class $\mathrm{G} \alpha$ proteins can activate the phospholipase $C-\beta$ (PLC- $\beta$ ) pathway that leads to the cleavage of phosphatidylinosiatol 4,5-biphosphate (PIP2) into inositol triphosphate (IP3) and diacylglycerol (DAG), and regulate intracellular $\mathrm{Ca}^{2+}$ release as well as protein kinase $\mathrm{C}$ (PKC) activity $[77,79]$. CaSR acts as a calcium detector of extracellular $\mathrm{Ca}^{2+}$ and functions to maintain intracellular $\mathrm{Ca}^{2+}$ homeostasis through the $G_{\alpha q / 11}$ pathway [80]. Frizzled receptors are activated by Wnt ligands, which triggers at least three distinct intracellular signaling cascades: betacatenin pathway (canonical), $\mathrm{Ca}^{2+}$ pathway (noncanonical) and planar polarity pathway. All three pathways are implicated in bone formation [81, 82], with the canonical pathway leading to the expression of osteoblast-specific gene marker [83], $\mathrm{Ca}^{2+}$ pathway leading to intracellular $\mathrm{Ca}^{2+}$ increase [84], and the planar polarity pathway leading to the activation of Rho/Rac GTPases and cytoskeletal reorganization [85]. We demonstrated for the first time that RGS2 and RGS4 play apposing roles during osteogenic differentiation of hMSCs, with RGS4 as a negative regulator and RGS2 as a positive regulator. Their role was partly mediated by modulating the expression of known osteogenic regulator Runx2. However, it is also possible that the effect brought on by siRGS2 and siRGS4 was mediated through modulating the $\mathrm{G} \alpha$ protein activities downstream of the above mentioned GPCR mediated signals and potentially others as well to regulate the differentiation and maturation of osteoblasts. It is also interesting to note that the uncovered roles of RGS4 and RGS2 during osteogenesis concur with their expression pattern during normal osteogenic differentiation, with RGS4 downregulated and RGS2 upregulated upon osteogenic initiation. Our study demonstrates that RGS proteins are important regulators of bone remodeling by regulating not only osteoclastogenesis but also osteogenesis.

Lastly, it is interesting to point out that unlike RGS2, which demonstrated a clear correlation between its $m R N A$ expression level and protein expression level in response to $S i R G S 2$ transfection, down regulation of RGS4 appeared much delayed and weaker at the protein level as compared to the $m R N A$ level in response to siRGS4 transfection. This implies different expression regulation kinetics between RGS2 and RGS4, with the latter likely having long half-life that could mask the effect of total reduced RGS4 transcripts. It is also possible that there might be unknown post-transcriptional regulation that hinders the progress of translation or posttranslational protein modifications that might render the RGS4 antibodies used incapable of recognizing modified forms of RGS4, obscuring the actual total protein level. Poor correlation between expression levels of $m R N A$ and protein level has been well documented [86-88], although in very few cases, the precise mechanisms have been investigated. This differential expression regulation of RGS2 and RGS4 adds another dynamic to the complexity of their roles during adipogenic and osteogenic differentiation of hMSCs.

GPCRs compose the largest family of membrane receptors and as a result, they are also the most widely targeted membrane proteins, with estimated $40 \%$ of clinical drugs targeting this system. As downstream regulators of these proteins, RGS proteins are likely to play essential roles during a wide range of developmental processes as well. During normal development, hMSCs residing in the adipose tissue as well as in the bone marrow would respond to different external stimuli by self-renewing or undergoing adipogenic or osteogenic differentiation. Some of these signals are mediated through the GPCR proteins. It is conceivable that RGS proteins might serve as factors of a feedback regulatory loop, in which that active differentiation would lead to expression change in these proteins such as RGS2 and RGS4, which in return would modulate the activity of their respective GPCR proteins in order to help attenuate/ augment the cells' further response to the external stimuli. How these proteins achieve regulatory specificity with different GPCRs and how they may interact with each other to fine tune specific biological event would be of great interest for future studies, as they are potentially druggable molecular targets for treating various physiological diseases.

\section{Conclusions}

In summary, our results demonstrate that RGS2 and RGS4 are differentially regulated during adipogenic and osteogenic differentiation of hMSCs, with both playing positive roles during adipogenesis but opposing roles during osteogenesis. We demonstrated: (I) expression of RGS2 and RGS4 were found to be inversely regulated during adipogenesis, with RGS2 up-regulated and RGS4 down-regulated in response to adipogenic induction; (II) RGS2 expression was also up-regulated during osteogenesis, whereas RGS4 expression was down-regulated during the first $48 \mathrm{~h}$ of osteogenesis followed by up-regulation afterwards; (III) expression of RGS2 and RGS4 was regulated by DEX and IBMX independent of Insulin during adipogenesis, but only by DEX during osteogenesis; (IV) expression knock-down using siRNA against $R G S 2$ or RGS4 both resulted in decreased adipogenic differentiation, though only knock-down of RGS4 appeared to 
have significant effect on the expression of examined adipogenic markers including $C / E B P \alpha$ and LPL; and lastly, (V) expression knock-down of RGS2 and RGS4 resulted in decreased and increased osteogenic differentiation respectively, indicating that RGS2 is normally a positive regulator while RGS4 is a negative regulator during osteogenesis. Our study demonstrates for the first time that RGS2 and RGS4 are inversely regulated during human adipogenesis even though they both play positive roles, and on the other hand, both genes were also inversely regulated during early human osteogenesis (first $48 \mathrm{~h}$ ) but play opposing roles. This implies that members of RGS proteins may play multifaceted roles during human adipogenesis and osteogenesis to balance or counterbalance each other's function during those processes.

\section{Methods}

\section{Cell culture}

Human adipose-derived mesenchymal stem cells (adhMSCs; Fisher Scientific, cat\# SV3010201) were cultured using Hyclone Advance STEM Mesenchymal Expansion Kit (Complete Media, Hyclone CM; Fisher Scientific, cat\# SH30875KT) and grown and cultured in a $5 \% \mathrm{CO}_{2}$ incubator at $37{ }^{\circ} \mathrm{C}$. Cells were expanded at 1:5 splitting ratio using $0.05 \%$ trypsin-EDTA (Corning, cat\# 25-02) and used at passage 4 for all assays.

\section{Clonogenicity assay}

hMSCs at P4 passage were plated at 100 cells per $10-\mathrm{cm}$ plate or 96 cells per 96 -well plate ( 1 cell/well) and cultured continuously for 21 days, with media change every 3 days. Cells were then rinsed with PBS after medium removal and stained with $0.5 \%$ crystal violet (Sigma Aldrich, cat\# 6158 ) dissolved in $20 \%$ methanol for $30 \mathrm{~min}$ at room Temperature (RT). Colonies containing in excess of 50 cells were counted using a Leica dissecting microscope.

\section{Immunostaining}

hMSCs at P4 passage were fixed with $4 \%$ paraformaldehyde for $10 \mathrm{~min}$, rinsed three times with PBS, permeated with $0.25 \%$ Triton X-100 in PBS for 10 min at RT, washed four times with PBS, 5 min each with gentle shaking, blocked with $1 \%$ BSA in PBS for $1 \mathrm{~h}$ at RT, incubated with primary antibodies diluted in blocking solution overnight at $4{ }^{\circ} \mathrm{C}$, followed by incubation with secondary antibodies also diluted in blocking solution for $1 \mathrm{~h}$ at RT. Images were obtained using Olympus IX50 fluorescence microscope. Primary antibody against CD73 (dilution 1:5) and CD105 (dilution 1:12.5) were from Thermofisher (cat\# 41-0200 and PA516895 respectively). Goat anti-mouse Alexa Fluor Plus 488 secondary antibody was from Thermofisher (cat\# A32723) (dilution 1:500) and Donkey anti-Rabbit FITC secondary antibody (dilution 1:500) was from R\&D (cat\# 711-095-152).

\section{Flow cytometry}

Detailed procedure can be found in our previously published study [89]. Briefly, hMSCs at P4 passage were collected and centrifuged at $1000 \mathrm{rpm}$ for five minutes. The pellet was resuspended in $3 \mathrm{ml} /$ well wash buffer $(98 \%$ PBS $+2 \%$ Fetal Calf Serum) and counted with Countess Automated Cell Counter (C10227, Life Technologies). About $4.5 \times 10^{5}$ cells in $100 \mu \mathrm{l}$ were aliquoted into each FACS tube (coated with $1 \%$ BSA overnight at $4{ }^{\circ} \mathrm{C}$ prior), and $5 \mu \mathrm{l}$ of each labeled primary antibody was added in each tube for staining for $30 \mathrm{~min}$ at $4{ }^{\circ} \mathrm{C}$. Cells were stained with FITC anti-human CD90 (cat\# 328107, Biolegend) alone, Pacific Blue anti-human CD73 (cat\# 344011, Biolegend) alone, or both together for $30 \mathrm{~min}$ at $4{ }^{\circ} \mathrm{C}$. FITC Mouse IgG1 (cat\# 400109, Biolegend) was used as isotype controls. Unstained hMSCs were also used as negative controls. Cells were then fixed with $2 \%$ paraformaldehyde for $30 \mathrm{~min}$ at RT, washed with PBS once before flow cytometry analysis. Flow cytometry data was acquired through a Gallios flow cytometer (Beckman Coulter) at the City of Hope Analytical cytometry core and analyzed using the FlowJo software by Tree Star Inc.

\section{Cellular differentiation conditions}

For all experimental assays, 64,000 cells were evenly plated in 24 well plates and media was changed every $48 \mathrm{~h}$ during differentiation induction unless specified otherwise. For adipogenic induction, ad-hMSCs were cultured in growth media supplemented with 0.2 or $1.0 \mu \mathrm{M}$ dexamethasone (Dex; Sigma, cat\# BCBP9963V), $0.45 \mu \mathrm{M}$ 3-isobutyl-1-methylxanthine (IBMX; Sigma, cat\# 15879), and $10 \mu \mathrm{g} / \mathrm{ml}$ insulin (Sigma Aldrich, cat\# SLBN8658V) for 12-16 days. Depending on experimental needs, three different types of growth media were used: Hyclone CM, Heat-Inactivated Fetal Bovine Serum (FBS)-based complete media (HI-FBS CM), or FBS-based complete media (FBS CM). Hyclone CM refers to Hyclone Advance STEM Mesenchymal Expansion Kit used to grow and expand ad-hMSCs (Fisher Scientific, cat\# SH30875KT), whose composition is undisclosed. HI-FBS CM and FBS CM were composed of High Glucose Dulbecco's Modified Eagle's Medium (DMEM), GlutaMAX (Gibco, cat\# 10566-16), 1\% non-essential amino acids (Gibco, cat\# 11149-050), with $10 \%$ fetal bovine serum (FBS; Corning, cat\# 35-010-CV) that was heat-inactivated or untreated, respectively. Heat-activation was performed in $57^{\circ} \mathrm{C}$ water bath for $30 \mathrm{~min}$. For osteogenic differentiation, ad-hMSCs were cultured in Hyclone CM supplemented with 0.2 or $1.0 \mu \mathrm{M}$ dexamethasone, $10 \mathrm{mM}$ $\beta$-glycerolphosphate (Sigma, cat\# G9422), and $0.05 \mathrm{mM}$ 2-phospho-L-ascorbic acid (Sigma, cat\# BCBP8162V) for $18-26$ days. 


\section{SiRNA reverse transfections}

Two transfection methodologies, referred to as reverse and forward transfection, were examined to optimize transfection efficiency. Forward transfection was achieved by equal plating of cells into culture vessel followed by introduction of siRNA-transfection agent complex at designed time point. Reverse transfection was achieved by introduction of siRNA-transfection reagent complex to culture vessel followed by equal plating of cells. Lyophilized $\operatorname{siRNA}$ at $1 \mathrm{nmol}$ quantity was suspended in $100 \mu \mathrm{l}$ of RNAase-free water obtaining a stock concentration of $10 \mu \mathrm{M}$, which was further diluted to $2 \mu \mathrm{M}$ working stock $(1 \mu \mathrm{l}$ of $2 \mu \mathrm{M}$ siRNA is equivalent to about $28 \mathrm{ng}$ of $\operatorname{siRNA}$ ). Transfection was done in 24-well plates. In reverse transfection, for each individual well, siRNA-transfection reagent complexes were prepared by adding $2.24 \mu \mathrm{l}$ xtremeGENE siRNA transfection reagent (Roche, cat\# 04476093001) into a tube containing $224 \mu \mathrm{l}$ MEM basal media (Corning, cat\# 10-022-CV), followed by the addition of $1.6 \mu \mathrm{l}$ of $2 \mu \mathrm{M}$ siRNA within $5 \mathrm{~min}$. The complex was incubated for 25-30 min inside a cell culture hood at room temperature before transferring to a designated well. A total of 64,000 cells in $640 \mu$ l of growth media would be added to the mixture, followed by $24-\mathrm{h}$ incubation in $\mathrm{CO}_{2}$ incubator before the media was exchanged for Hyclone CM growth media. The cells were further incubated for $24 \mathrm{~h}$ before subjecting to adipogenic or osteogenic differentiation induction. The following siRNA were used in this study: siCON: AllStars Neg. siRNA (Qiagen, cat\# 1027284); siRGS2-2: Hs_RGS2_2 (Qiagen, cat\# SI00045773); siRGS2-3: Hs_RGS2_3 (Qiagen, cat\# SI00045780); siRGS4-8: Hs_RG4_8 (Qiagen, cat\# SI03028018); and siRGS4-10: Hs_RG4_10 (Qiagen, cat\# SI03097766).

\section{DAPI staining and total cell count}

Nuclear staining was achieved using DAPI (4',6-diamidino-2-phenylindole) nucleic acid stain (Sigma, cat\# 108K4024). A working solution was prepared by diluting 1:3000 of a $14.3 \mathrm{mM}$ DAPI stock in $1 \times$ PBS. Briefly, cells were fixed with $10 \%$ buffered formalin phosphate, washed three times with distilled water, and stained with the diluted DAPI solution for $30 \mathrm{~min}$ at room temperature. Cultures were then washed three times with distilled water and images were acquired using Olympus IX50 fluorescence microscope (7 images per well at 100× magnification were taken). Nuclear counts of each image were done using CellProfiler Image Analysis Software [90].

\section{Alizarin red staining and quantification}

Mature osteocytes secrete calcium phosphate were detected 18-24 days after osteogenic induction using a
2\% Alizarin Red S Staining solution (Acros Organic, cat\# 130-22-3) ( $\mathrm{pH} 4.1-4.3$ adjusted with $0.5 \%$ Ammonium hydroxide). Cells were first fixed by $10 \%$ formalin-PBS, rinsed twice with water, incubated with Alizarin Red $\mathrm{S}$ solution for $10 \mathrm{~min}$, washed four times with distilled water with 5 min intervals between wash, and air dried for later imaging and quantification. For quantification, a modified manufacturer's protocol of an osteogenesis quantitation kit (Millipore, ECM815) was used. Briefly, dried stained cultures were incubated with $10 \%$ acetic acid for $20 \mathrm{~min}$ at room temperate. The loosely attached monolayer was then scrapped and total well content was transferred to microcentrifuge tubes. The mixtures were vortexed vigorously, parafilmed, and incubated at $85{ }^{\circ} \mathrm{C}$ for $10 \mathrm{~min}$, followed by incubation on ice for $5 \mathrm{~min}$ and subsequent centrifugation at $20,000 \times g$ for $15 \mathrm{~min}$. Supernatant was then transferred to a new microcentrifuge tube. Optical densities of solutions were measured at 405 and $690 \mathrm{~nm}$ in an ELx800 96 well plate reader (BioTek).

\section{Oil-Red-O staining and quantification}

Lipid droplets in mature adipocytes can be identified using Oil-Red-O staining solution. After fixing with $10 \%$ buffered formalin phosphate (Fisher Scientific, cat\# SF100-4), cells were incubated with $100 \%$ propylene glycol (Amresco, cat\# 0575) for $5 \mathrm{~min}$ at room temperature, followed by its removal and staining with Whatman filter paper-filtered Oil Red O solution (Electron Microscopy Sciences, cat\# 36609-01) for $30 \mathrm{~min}$ to $2 \mathrm{~h}$ with gentle rocking. Next, staining solution was removed and cells were incubated with $85 \%$ propylene glycol (Fisher Scientific, cat\# A426P) for 5 min, followed by rinsing in distilled water three times. Stained cells would remain covered in distilled water, parafilmed and stored at $4{ }^{\circ} \mathrm{C}$ refrigerator. Whole-well images were taken using a Leica dissection microscope. For Oil-Red-O staining quantification, cells samples were air dried overnight after removing water and Oil-Red-O stain was extracted using $150 \mu \mathrm{l} /$ well (24-well plate) $100 \%$ isopropyl alcohol for $1 \mathrm{~min}$. Optical density readings for extracted stain solution were measured at 510 and $690 \mathrm{~nm}$ in an ELx800 96 well plate reader (BioTek).

\section{Adipocyte cell counts and area measurements of stained oil droplets}

To determine total adipocyte and total cell counts, wells were imaged using an Olympus IX50 microscope at 100× magnification after double staining cultures with both DAPI and OilRedO stain. Images were taken starting from the bottom to the top of each individual well, resulting in seven separate fields of view spanning the entire well. DAPI stain showing nuclear stain were imaged using UVlight as excitation light (emission light: blue fluorescence) 
and OilRedO stain was imaged using green light as excitation light (emission light: red fluorescence). For adipocyte count, DAPI and OilRedO images taken in the same field of view were merged using Adobe Photoshop and mature adipocytes (identified by large concentration of oil droplets) were manually counted in Photoshop CS6 (Adobe).

For total area measurements of stained oil droplets, phase contrast images of OilRedO stained cells were taken and processed through an imaging analysis software (ImagePro Plus 7.2), which outlined the stained oil droplets of mature and immature adipocytes resulting in quantitative area measurements. Total area measurements of stained oil droplets were summed for each well and the average area measurement for each treatment group (12 wells/group) was then calculated and graphed relative to control group.

\section{RT-PCR analysis}

For all cell pelleting, cells were detached with $0.05 \%$ Trypsin-EDTA, washed twice with $1 \times$ PBS and stored at $-80^{\circ} \mathrm{C}$ until RNA extraction. Total RNA was isolated from all treatment groups using RNeasy Kit (Qiagen, cat\# 74134). Equal concentrations of RNA (50 or $100 \mathrm{ng}$ ) was then reverse transcribed into cDNA using Superscript III Reverse Transcriptase Kit (Fisher Scientific, cat\# 11752). PCR amplification was conducted using HotStarTaq Polymerase (Qiagen, cat\# 203645). Primers for HPS90-beta (control), RGS2, RGS4, adipogenic markers (CEBPa, PPARy, \& LPL), osteogenic markers (Osteocalcin, Runx2, and ALPL) and cell cycle markers (CDK1, CDK4, CCND1, CDK2) are listed in Table 1. PCR product gel images were obtained using SYBR safe DNA gel stain (Fisher Scientific, cat\# 1760400) and Gel Doc XR+ system (BioRad). For all treatment groups, duplicates or triplicates as indicated were ran and analyzed. Quantifications are reported as average expression for each gene of interest normalized to HSP90 and made relative to control \pm standard deviations.

\section{Western Blot}

Protein was extracted from whole cell lysis from $5.6 \times 10^{5}$ cells per treatment group on day $1,2,3,4,5$ or 7 (for RGS4 detection), or day 1, 2 or 3 (for RGS2 detection) post AIM or OIM treatment initiation. Briefly, Protein was extracted using M-PER reagent (Thermofisher cat\# 78501) containing $1 \times$ Halt protease inhibitor (Thermofisher cat\# 87785). About $20 \mu \mathrm{g}$ of protein per sample was loaded and separated in NuPAGE $10 \%$ bis-tris gel (Thermofisher cat\# NP0301BOX). After transferring to nitrocellulose membrane, the blot was incubated in antigen pretreatment solution (SuperSignal Western Blot Enhancer kit, Thermofisher cat\# 46640) for $10 \mathrm{~min}$ before incubating in StartingBlock blocking buffer (Thermofisher cat\# 37543) for $30 \mathrm{~min}$ at RT, followed by incubation with primary antibody raised in mouse (Santa Cruz Biotechnology, HSP90 F-8, sc-13119; RGS4 H-12, sc398348; RGS4 D-8, sc398658; and RGS2 BC-43, sc-100761) and HRP-conjugated anti-mouse secondary antibody (Thermofisher, Cat\# 31503) for $1 \mathrm{~h}$ each at RT with gentle shaking. RGS4 H-12 detects isoform $3(34 \mathrm{kDa})$ whereas RGS D-8 detects isoforms 1 and 2 $(23 \mathrm{kDa})$. To detect protein bands, blot was incubated in chemiluminescent substrate working solution (SuperSignal West Pico PLUS Chemiluminescent substrate kit, Thermofisher cat\#34577) overnight at $4{ }^{\circ} \mathrm{C}$, and images were acquired and bands were quantified using Gel Doc $\mathrm{XR}+$ system (BioRad).

Table 1 Primer sequences and associated PCR conditions

\begin{tabular}{|c|c|c|c|c|}
\hline & Forward sequence & Reverse sequence & Product size (bps) & Annealing $\operatorname{Tm}\left({ }^{\circ} \mathrm{C}\right)$ \\
\hline HSP90-beta & TACTTGGTGGCAGAGAAAGT & CTCATCTGAACCCACATCTT & 441 & 60 \\
\hline RGS2 & CAAACAGCCGGGACTCCAGC & TGCTGGCATGCAGCTGGTCA & 303 & 63.5 \\
\hline RGS4 & TCCCTGGTCCCTCAGTGTGCC & AAGCATGCCCTGAGCACCCA & 958 & 64 \\
\hline PPARY & AAGCCCTTCACTACTGTTGA & ACCTGATGGCATTATGAG AC & 444 & 56 \\
\hline CEBPa & CCTAAGGTTGTTCCCCTAGT & GAGAGTCTCATTTTGGCAAG & 547 & 58 \\
\hline LPL & GTCCGTGGCTACCTGTCATT & AGCCCTTTCTCAAAGGCTTC & 717 & 60 \\
\hline Runx2 & TCTTCACAAATCCTCCCC & TGGATTAAAAGGACTTGGTG & 230 & 55 \\
\hline OC & CTACCTGTATCAATGGCTG & CAGATTCCTCTTCTGGAGTTTA & 310 & 56 \\
\hline ALPL & TGGAGCTTCAGAAGCTCAACA & ATCTCGTTGTCTGAGTACCAG & 450 & 60 \\
\hline CDK1 & GGATCTACCATACCCATTGAC & CCATGTACTGACCAGGAGGG & 327 & 55 \\
\hline CDK2 & TGACTCGCCGGGCCCTATTCC & CCCAAGGCCAAGCCTGGTCA & 381 & 60 \\
\hline CDK4 & AGTTTCCGCGCGCCTCTTTG & GGCACAGACGTCCATCAGCCG & 455 & 63 \\
\hline CCND1 & CTCCAGAGGGCTGTCGG & CTCGGCCGTCAGGGGGA & 528 & 60 \\
\hline Runx2/p57 & CGC CTC ACA AAC AAC CAC AG & TCA CTG TGC TGA AGA GGC TG & 225 & 60 \\
\hline
\end{tabular}




\section{Statistical analysis}

All graph data is presented as the average \pm standard deviations (SD). Differences in data was considered significant if $\mathrm{p}<0.05$ as determined by student's unpaired $\mathrm{t}$ test. $\mathrm{p}$ value was determined by comparing original raw data sets between treatment and control groups, prior to percentage calculation set relative to $s i C O N$ as shown in graphs.

\section{Additional files}

Additional file 1: Figure S1. Clonogenic Assay of Adipose-Derived hMSCs. The number of clones with more than 50 cells after 21 days of culture was counted and representative images of clones and non-clones are included as well. Error bars represent variation among triplicates in each independent repeat $(n=3)$.

Additional file 2: Figure S2. Expression Profile of hMSC markers CD73, CD90 and CD105 by Immunostaining and Flow Cytometry. Expression of both CD73 and CD105 were detected in $\geq 95 \%$ of the cells. Expression of $\mathrm{CD} 73$ was further confirmed by flow cytometry and co-staining with CD90, which also showed expression in $\geq 95 \%$ of the cells.

Additional file 3: Figure S3. Temporal Expression of RGS4 and RGS2 in HI-FBS CM based AIM and OIM Treatments. Expression of RGS2 and RGS4 was examined by RT-PCR in hMSCs cultured in 8 different media treatments, including Hyclone CM, HI-FBS CM, Hyclone CM based DEX media

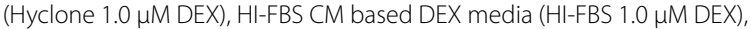
Hyclone CM based AIM media with 1.0 $\mu$ M DEX (Hyclone 1.0 $\mu$ M DEX AIM),

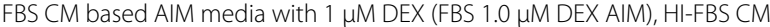
based AIM media with 1.0 $\mu \mathrm{M}$ DEX (HI-FBS $1.0 \mu \mathrm{M}$ DEX AIM), and Hyclone

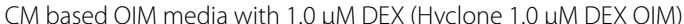
Expression in each treatment condition was examined at six different time points, including D0.5, D1, D1.5, D2, D3 and D4 post initial treatment. A Graph of RGS4 expression. B Graph of RGS2 expression. Graphs represent average gene expression level normalized to that of HSP9O and set relative to $C M$ control at each given time point $(n=2)$.

Additional file 4: Figure S4. Efficiency of siRNA transfection in adipose-derived hMSCs. Ad-hMSCs were reverse transfected with either a scrambled siCON or siTOX at $16.5 \mathrm{nM}$. A Bright field images of transfected cells at day 1,2,6 and 12 post siRNA transfection. B Total live cells were determined using an automated cell counter at day 1,2, 6 or 12 days post siRNA transfection. Graphed data is shown as mean $\pm S D(n=3)$. Asterisks represent significant differences between siTOX and siCON treated cells $(* * p<0.01)$

Additional file 5: Figure S5. Expression knockdown of RGS4 and RGS2 at the protein level by siRGS4 and siRGS2, respectively. A. Western blot demonstrating expression of RGS4 detected by two different antibodies that recognized isoform $3(34 \mathrm{kDa})$ and isoforms 1 \& 2 (23 kDa) respectively in both siRGS4 and siCON treatment groups on day 7 post OIM initiation. $(n=2)$. B Western blot demonstrating expression of RGS2 detected by its antibody that recognized all isoforms at around $26 \mathrm{kDa}$ in both siRGS2 and siCON treatment groups on day 2 post OIM initiation $(n=2)$.

Additional file 6: Figure S6. Expression knockdown of RGS2 mRNA by siRGS2 during adipogenic differentiation of hMSCs induced by HI-FBS CM based adipogenic media. Expression of RGS2 was examined at day 1, 3, 5, 7, and 14 after differentiation initiation at $48 \mathrm{~h}$ post siRGS2 transfection. A Expression level of RGS2 in each treatment group was determined relative to their expression in siCON control group, after normalization against internal control HSP9O at each given time point. B Agarose gel images of RGS2 and HSP90 RT-PCR products were shown. Error bars represent variation between independent repeats $(n=2)$. ${ }^{*} p<0.05$, ${ }^{* *} p<0.01$. Expression comparison was made between siCON and siRGS2 treatment groups at each time point.

\section{Authors' contributions}

AM performed most of the experiments included in this study while LT and YXZ performed the remaining. All authors analyzed and interpreted experimental data. AM and YXZ contributed to writing the manuscript. All authors read and approved the final manuscript.

\section{Author details}

${ }^{1}$ Biological Sciences Department, California State Polytechnic University at Pomona, 3801 W. Temple Ave., Pomona, CA 91768, USA. ${ }^{2}$ Present Address: Center for Biomedicine and Genetics, Beckman Research Institute of City of Hope, 1500 E. Duarte Rd., Duarte, CA 91010, USA.

\section{Acknowledgements}

Not applicable.

\section{Competing interests}

The authors declare that they have no competing interests.

\section{Availability of data and materials}

All data generated or analyzed during this study are included in this published article and its supplementary information files.

\section{Consent for publication}

Not applicable.

\section{Ethics approval and consent to participate}

Not applicable.

\section{Funding}

This work was supported by NIH Grants Nos. 1SC3GM094078 and 1SC3GM1 16720, both awarded to YX Zhao. Alma Madrigal was a 2015-2016 fellowship recipient of the NIH MBRS-RISE project (1R25GM113748) awarded to California State Polytechnic University at Pomona. No additional external funding was received for this study.

\section{Publisher's Note}

Springer Nature remains neutral with regard to jurisdictional claims in published maps and institutional affiliations.

Received: 18 April 2017 Accepted: 14 December 2017

Published online: 26 December 2017

\section{References}

1. Lowe CE, O'Rahilly S, Rochford JJ. Adipogenesis at a glance. J Cell Sci. 2011;124(Pt 16):2681-6. https://doi.org/10.1242/jcs.079699 (Epub 2011/08/03).

2. Cristancho $A G$, Lazar MA. Forming functional fat: a growing understanding of adipocyte differentiation. Nat Rev Mol Cell Biol. 2011;12(11):722-34. https://doi.org/10.1038/nrm3198 (Epub 2011/09/29)

3. Zhang $\mathrm{R}$, Wang $\mathrm{D}, \mathrm{Xia} Z$, Chen $\mathrm{C}$, Cheng $\mathrm{P}$, Xie $\mathrm{H}$, et al. The role of microRNAs in adipocyte differentiation. Front Med. 2013;7(2):223-30. https://doi. org/10.1007/s1 1684-013-0252-8 (Epub 2013/04/23).

4. Qian SW, Li X, Zhang YY, Huang HY, Liu Y, Sun X, et al. Characterization of adipocyte differentiation from human mesenchymal stem cells in bone marrow. BMC Dev Biol. 2010;10:47. https://doi.org/10.1186/1471213X-10-47 (Epub 2010/05/13).

5. Wu Z, Rosen ED, Brun R, Hauser S, Adelmant G, Troy AE, et al. Crossregulation of C/EBP alpha and PPAR gamma controls the transcriptional pathway of adipogenesis and insulin sensitivity. Mol Cell. 1999;3(2):151-8 (Epub 1999/03/17)

6. MacDougald OA, Lane MD. Transcriptional regulation of gene expression during adipocyte differentiation. Annu Rev Biochem. 1995;64:345-73. https://doi.org/10.1146/annurev.bi.64.070195.002021 (Epub 1995/01/01)

7. Tontonoz $\mathrm{P}, \mathrm{Hu}$ E, Spiegelman BM. Stimulation of adipogenesis in fibroblasts by PPAR gamma 2, a lipid-activated transcription factor. Cell. 1994;79(7):1147-56 (Epub 1994/12/30). 
8. Freytag SO, Paielli DL, Gilbert JD. Ectopic expression of the CCAAT/ enhancer-binding protein alpha promotes the adipogenic program in a variety of mouse fibroblastic cells. Genes Dev. 1994;8(14):1654-63 (Epub 1994/07/15)

9. Chen Q, Shou P, Zheng C, Jiang M, Cao G, Yang Q, et al. Fate decision of mesenchymal stem cells: adipocytes or osteoblasts? Cell Death Differ. 2016;23(7):1128-39. https://doi.org/10.1038/cdd.2015.168.

10. Huang C, Geng J, Jiang S. MicroRNAs in regulation of osteogenic differentiation of mesenchymal stem cells. Cell Tissue Res. 2016. https://doi. org/10.1007/s00441-016-2462-2.

11. Fei $Y$, Hurley MM. Role of fibroblast growth factor 2 and Wnt signaling in anabolic effects of parathyroid hormone on bone formation. J Cell Physiol. 2012;227(11):3539-45. https://doi.org/10.1002/jcp.24075.

12. Vanderschueren $D$, Laurent MR, Claessens F, Gielen E, Lagerquist MK, Vandenput $L$, et al. Sex steroid actions in male bone. Endocr Rev. 2014;35(6):906-60. https://doi.org/10.1210/er.2014-1024.

13. Nakashima K, Zhou X, Kunkel G, Zhang Z, Deng JM, Behringer RR, et al. The novel zinc finger-containing transcription factor osterix is required for osteoblast differentiation and bone formation. Cell. 2002;108(1):17-29.

14. Ducy P, Zhang R, Geoffroy V, Ridall AL, Karsenty G. Osf2/Cbfa1: a transcriptional activator of osteoblast differentiation. Cell. 1997;89(5):747-54.

15. Takahashi T. Overexpression of Runx2 and MKP-1 stimulates transdifferentiation of 3T3-L1 preadipocytes into bone-forming osteoblasts in vitro. Calcif Tissue Int. 2011;88(4):336-47. https://doi.org/10.1007/ s00223-011-9461-9.

16. Arvidson K, Abdallah BM, Applegate LA, Baldini N, Cenni E, GomezBarrena $\mathrm{E}$, et al. Bone regeneration and stem cells. J Cell Mol Med. 2011;15(4):718-46. https://doi.org/10.1111/j.1582-4934.2010.01224.x.

17. Zhao Y, Ding S. A high-throughput siRNA library screen identifies osteogenic suppressors in human mesenchymal stem cells. Proc Natl Acad Sci USA. 2007;104(23):9673-8. https://doi.org/10.1073/pnas.0703407104.

18. Abdallah BM, Kassem M. New factors controlling the balance between osteoblastogenesis and adipogenesis. Bone. 2012;50(2):540-5. https:// doi.org/10.1016/j.bone.2011.06.030.

19. Beresford JN, Bennett JH, Devlin C, Leboy PS, Owen ME. Evidence for an inverse relationship between the differentiation of adipocytic and osteogenic cells in rat marrow stromal cell cultures. J Cell Sci. 1992;102(Pt 2):341-51.

20. Canalis E. Mechanisms of glucocorticoid-induced osteoporosis. Curr Opin Rheumatol. 2003;15(4):454-7.

21. Ali AA, Weinstein RS, Stewart SA, Parfitt AM, Manolagas SC, Jilka RL. Rosiglitazone causes bone loss in mice by suppressing osteoblast differentiation and bone formation. Endocrinology. 2005;146(3):1226-35. https://doi.org/10.1210/en.2004-0735.

22. Lu W, Wang W, Wang S, Feng Y, Liu K. Rosiglitazone promotes bone marrow adipogenesis to impair myelopoiesis under stress. PLoS ONE. 2016;11(2):e0149543. https://doi.org/10.1371/journal.pone.0149543.

23. Rzonca SO, Suva $\sqcup$, Gaddy D, Montague DC, Lecka-Czernik B. Bone is a target for the antidiabetic compound rosiglitazone. Endocrinology. 2004;145(1):401-6. https://doi.org/10.1210/en.2003-0746.

24. Cohen A, Dempster DW, Stein EM, Nickolas TL, Zhou H, McMahon DJ, et al. Increased marrow adiposity in premenopausal women with idiopathic osteoporosis. J Clin Endocrinol Metab. 2012;97(8):2782-91. https://doi.org/10.1210/jc.2012-1477.

25. Bethel M, Chitteti BR, Srour EF, Kacena MA. The changing balance between osteoblastogenesis and adipogenesis in aging and its impact on hematopoiesis. Curr Osteoporos Rep. 2013;11(2):99-106. https://doi. org/10.1007/s11914-013-0135-6.

26. Justesen J, Stenderup K, Ebbesen EN, Mosekilde L, Steiniche T, Kassem M. Adipocyte tissue volume in bone marrow is increased with aging and in patients with osteoporosis. Biogerontology. 2001;2(3):165-71.

27. Meunier P, Aaron J, Edouard C, Vignon G. Osteoporosis and the replacement of cell populations of the marrow by adipose tissue. A quantitative study of 84 iliac bone biopsies. Clin Orthop Relat Res. 1971;80:147-54.

28. Moerman EJ, Teng K, Lipschitz DA, Lecka-Czernik B. Aging activates adipogenic and suppresses osteogenic programs in mesenchymal marrow stroma/stem cells: the role of PPAR-gamma2 transcription factor and TGF-beta/BMP signaling pathways. Aging Cell. 2004;3(6):379-89. https:// doi.org/10.1111/j.1474-9728.2004.00127.x.
29. Pittenger MF, Mackay AM, Beck SC, Jaiswal RK, Douglas R, Mosca JD, et al. Multilineage potential of adult human mesenchymal stem cells. Science. 1999;284(5411):143-7.

30. Scott MA, Nguyen VT, Levi B, James AW. Current methods of adipogenic differentiation of mesenchymal stem cells. Stem Cells Dev. 2011;20(10):1793-804. https://doi.org/10.1089/scd.2011.0040 (Epub 2011/04/30).

31. Ong WK, Sugii S. Adipose-derived stem cells: fatty potentials for therapy. Int J Biochem Cell Biol. 2013;45(6):1083-6. https://doi.org/10.1016/j. biocel.2013.02.013 (Epub 2013/03/06).

32. Tran TT, Kahn CR. Transplantation of adipose tissue and stem cells: role in metabolism and disease. Nat Rev Endocrinol. 2010;6(4):195-213. https:// doi.org/10.1038/nrendo.2010.20 (Epub 2010/03/03).

33. Siddappa R, Fernandes H, Liu J, van Blitterswijk C, de Boer J. The response of human mesenchymal stem cells to osteogenic signals and its impact on bone tissue engineering. Curr Stem Cell Res Ther. 2007;2(3):209-20.

34. Yamaguchi DT. "Ins" and "Outs" of mesenchymal stem cell osteogenesis in regenerative medicine. World J Stem Cells. 2014;6(2):94-110. https://doi. org/10.4252/wjsc.v6.i2.94

35. Zhang J, Chen J. Bone tissue regeneration-application of mesenchymal stem cells and cellular and molecular mechanisms. Curr Stem Cell Res Ther. 2017;12(5):357-64. https://doi.org/10.2174/15748 $88 \times 11666160921121555$

36. Siderovski DP, Willard FS. The GAPs, GEFs, and GDIs of heterotrimeric G-protein alpha subunits. Int J Biol Sci. 2005;1 (2):51-66.

37. Ross EM, Wilkie TM. GTPase-activating proteins for heterotrimeric $G$ proteins: regulators of $\mathrm{G}$ protein signaling (RGS) and RGS-like proteins. Annu Rev Biochem. 2000;69:795-827. https://doi.org/10.1146/annurev. biochem.69.1.795.

38. Heximer SP. A "new twist" on RGS protein selectivity. Structure. 2013;21(3):319-20. https://doi.org/10.1016/j.str.2013.02.011.

39. Xu X, Zeng W, Popov S, Berman DM, Davignon I, Yu K, et al. RGS proteins determine signaling specificity of Gq-coupled receptors. J Biol Chem. 1999;274(6):3549-56

40. Hollinger S, Hepler JR. Cellular regulation of RGS proteins: modulators and integrators of G protein signaling. Pharmacol Rev. 2002;54(3):527-59.

41. Osei-Owusu P, Owens EA, Jie L, Reis JS, Forrester SJ, Kawai T, et al. Regulation of renal hemodynamics and function by RGS2. PLoS ONE. 2015;10(7):e0132594. https://doi.org/10.1371/journal.pone.0132594.

42. Osei-Owusu P, Blumer KJ. Regulator of G protein signaling 2: a versatile regulator of vascular function. Prog Mol Biol Transl Sci. 2015;133:77-92. https://doi.org/10.1016/bs.pmbts.2015.02.001.

43. Xie Y, Wolff DW, Wei T, Wang B, Deng C, Kirui JK, et al. Breast cancer migration and invasion depend on proteasome degradation of regulator of G-protein signaling 4. Cancer Res. 2009;69(14):5743-51. https://doi. org/10.1158/0008-5472.CAN-08-3564.

44. Gerber KJ, Squires KE, Hepler JR. Roles for regulator of G protein signaling proteins in synaptic signaling and plasticity. Mol Pharmacol. 2016;89(2):273-86. https://doi.org/10.1124/mol.115.102210.

45. Louwette S, Van Geet C, Freson K. Regulators of G protein signaling: role in hematopoiesis, megakaryopoiesis and platelet function. J Thromb Haemost. 2012;10(11):2215-22. https://doi. org/10.1111/j.1538-7836.2012.04903.x

46. Abramow-Newerly M, Roy AA, Nunn C, Chidiac P. RGS proteins have a signalling complex: interactions between RGS proteins and GPCRs, effectors, and auxiliary proteins. Cell Signal. 2006;18(5):579-91. https://doi. org/10.1016/j.cellsig.2005.08.010.

47. Keinan D, Yang S, Cohen RE, Yuan X, Liu T, Li YP. Role of regulator of G protein signaling proteins in bone. Front Biosci. 2014;19:634-48.

48. Iwai K, Koike M, Ohshima S, Miyatake K, Uchiyama Y, Saeki Y, et al. RGS18 acts as a negative regulator of osteoclastogenesis by modulating the acid-sensing OGR1/NFAT signaling pathway. J Bone Miner Res. 2007;22(10):1612-20. https://doi.org/10.1359/jbmr.070612.

49. Jules J, Yang S, Chen W, Li YP. Role of regulators of $G$ protein signaling proteins in bone physiology and pathophysiology. Prog Mol Biol Transl Sci. 2015;133:47-75. https://doi.org/10.1016/bs.pmbts.2015.02.002.

50. Deng W, Wang $X$, Xiao J, Chen $K$, Zhou H, Shen D, et al. Loss of regulator of $G$ protein signaling 5 exacerbates obesity, hepatic steatosis, inflammation and insulin resistance. PLoS ONE. 2012;7(1):e30256. https://doi. org/10.1371/journal.pone.0030256. 
51. Nunn C, Zhao P, Zou MX, Summers K, Guglielmo CG, Chidiac P. Resistance to age-related, normal body weight gain in RGS2 deficient mice. Cell Signal. 2011;23(8):1375-86. https://doi.org/10.1016/j.cellsig.2011.03.020.

52. Nishizuka M, Honda K, Tsuchiya T, Nishihara T, Imagawa M. RGS2 promotes adipocyte differentiation in the presence of ligand for peroxisome proliferator-activated receptor gamma. J Biol Chem. 2001;276(32):296257. https://doi.org/10.1074/jbc.C100272200.

53. Grillet N, Pattyn A, Contet C, Kieffer BL, Goridis C, Brunet JF. Generation and characterization of Rgs 4 mutant mice. Mol Cell Biol. 2005;25(10):4221-8. https://doi.org/10.1128/MCB.25.10.4221-4228.2005

54. lankova I, Chavey C, Clape C, Colomer C, Guerineau NC, Grillet N, et al. Regulator of $\mathrm{G}$ protein signaling-4 controls fatty acid and glucose homeostasis. Endocrinology. 2008;149(11):5706-12. https://doi.org/10.1210/ en.2008-0717.

55. Peltz L, Gomez J, Marquez M, Alencastro F, Atashpanjeh N, Quang T, et al. Resveratrol exerts dosage and duration dependent effect on human mesenchymal stem cell development. PLoS ONE. 2012;7(5):e37162. https://doi.org/10.1371/journal.pone.0037162 (Epub 2012/05/23).

56. Zilberfarb V, Siquier K, Strosberg AD, Issad T. Effect of dexamethasone on adipocyte differentiation markers and tumour necrosis factor-alpha expression in human PAZ6 cells. Diabetologia. 2001;44(3):377-86.

57. Langenbach F, Handschel J. Effects of dexamethasone, ascorbic acid and beta-glycerophosphate on the osteogenic differentiation of stem cells in vitro. Stem Cell Res Ther. 2013;4(5):117. https://doi.org/10.1186/scrt328.

58. Wang H, Eckel RH. Lipoprotein lipase: from gene to obesity. Am J Physiol Endocrinol Metab. 2009;297(2):E271-88. https://doi.org/10.1152/ ajpendo.90920.2008.

59. Neve A, Corrado A, Cantatore FP. Osteocalcin: skeletal and extra-skeletal effects. J Cell Physiol. 2013;228(6):1 149-53. https://doi.org/10.1002/ jcp.24278.

60. Millan JL, Whyte MP. Alkaline phosphatase and hypophosphatasia. Calcif Tissue Int. 2016;98(4):398-416. https://doi.org/10.1007/ s00223-015-0079-1.

61. Wang E, Nam HK, Liu J, Hatch NE. The effects of tissue-non-specific alkaline phosphatase gene therapy on craniosynostosis and craniofacial morphology in the FGFR2C342Y/+ mouse model of Crouzon craniosynostosis. Orthod Craniofac Res. 2015;18(Suppl 1):196-206. https://doi. org/10.1111/ocr.12080.

62. Martin JW, Zielenska M, Stein GS, van Wijnen AJ, Squire JA. The role of RUNX2 in osteosarcoma oncogenesis. Sarcoma. 2011;2011:282745. https://doi.org/10.1155/2011/282745.

63. Xie Z, Chan EC, Druey KM. R4 regulator of G protein signaling (RGS) proteins in inflammation and immunity. AAPS J. 2016;18(2):294-304. https:// doi.org/10.1208/s12248-015-9847-0.

64. Kroeze WK, Sheffler DJ, Roth BL. G-protein-coupled receptors at a glance. J Cell Sci. 2003;116(Pt 24):4867-9. https://doi.org/10.1242/jcs.00902.

65. Wettschureck N, Offermanns S. Mammalian G proteins and their cell type specific functions. Physiol Rev. 2005;85(4):1159-204. https://doi. org/10.1152/physrev.00003.2005.

66. Wilkie TM. G-protein signaling: satisfying the basic necessities of life. Curr Biol. 2000;10(23):R853-6.

67. Daudt R, Von Poser GL, Neves G, Rates SM. Screening for the antidepressant activity of some species of Hypericum from South Brazil. Phytother Res. 2000;14(5):344-6. [Erratum: Phytother Res. 2000;14(8):661].

68. De Vries L, Zheng B, Fischer T, Elenko E, Farquhar MG. The regulator of $G$ protein signaling family. Annu Rev Pharmacol Toxicol. 2000;40:235-71. https://doi.org/10.1146/annurev.pharmtox.40.1.235.

69. Zhong H, Wade SM, Woolf PJ, Linderman JJ, Traynor JR, Neubig RR. A spatial focusing model for $\mathrm{G}$ protein signals. Regulator of $\mathrm{G}$ protein signaling (RGS) protien-mediated kinetic scaffolding. J Biol Chem. 2003;278(9):7278-84. https://doi.org/10.1074/jbc.M208819200.

70. Boureux A, Vignal E, Faure S, Fort P. Evolution of the Rho family of ras-like GTPases in eukaryotes. Mol Biol Evol. 2007;24(1):203-16. https://doi. org/10.1093/molbev/msl145.

71. McBeath R, Pirone DM, Nelson CM, Bhadriraju K, Chen CS. Cell shape, cytoskeletal tension, and RhoA regulate stem cell lineage commitment. Dev Cell. 2004;6(4):483-95.
72. Vaque JP, Dorsam RT, Feng X, Iglesias-Bartolome R, Forsthoefel DJ, Chen Q, et al. A genome-wide RNAi screen reveals a Trio-regulated Rho GTPase circuitry transducing mitogenic signals initiated by G proteincoupled receptors. Mol Cell. 2013;49(1):94-108. https://doi.org/10.1016/j. molcel.2012.10.018.

73. Nobusue H, Onishi N, Shimizu T, Sugihara E, Oki Y, Sumikawa Y, et al. Regulation of MKL1 via actin cytoskeleton dynamics drives adipocyte differentiation. Nat Commun. 2014;5:3368. https://doi.org/10.1038/ ncomms4368.

74. Zhang Y, Khan D, Delling J, Tobiasch E. Mechanisms underlying the osteoand adipo-differentiation of human mesenchymal stem cells. Sci World J. 2012;2012:793823. https://doi.org/10.1100/2012/793823.

75. Luo X, Popov S, Bera AK, Wilkie TM, Muallem S. RGS proteins provide biochemical control of agonist-evoked $\left[\mathrm{Ca}^{2+}\right]$ i oscillations. Mol Cell. 2001;7(3):651-60.

76. Yang S, Li YP. RGS12 is essential for RANKL-evoked signaling for terminal differentiation of osteoclasts in vitro. J Bone Miner Res. 2007;22(1):45-54. https://doi.org/10.1359/jbmr.061007.

77. Taylor CW, Tovey SC. From parathyroid hormone to cytosolic $\mathrm{Ca}^{2+}$ signals. Biochem Soc Trans. 2012;40(1):147-52. https://doi.org/10.1042/ BST20110615.

78. Cheung R, Erclik MS, Mitchell J. Increased expression of G1 1alpha in osteoblastic cells enhances parathyroid hormone activation of phospholipase C and AP-1 regulation of matrix metalloproteinase-13 mRNA. J Cell Physiol. 2005;204(1):336-43. https://doi.org/10.1002/jcp.20299.

79. Toshima JY, Nakanishi J, Mizuno K, Toshima J, Drubin DG. Requirements for recruitment of a $\mathrm{G}$ protein-coupled receptor to clathrin-coated pits in budding yeast. Mol Biol Cell. 2009;20(24):5039-50. https://doi. org/10.1091/mbc.E09-07-0541.

80. Colella M, Gerbino A, Hofer AM, Curci S. Recent advances in understanding the extracellular calcium-sensing receptor. F1000Research. 2016;5. https://doi.org/10.12688/f1000research.8963.1.

81. Huang W, Yang S, Shao J, Li YP. Signaling and transcriptional regulation in osteoblast commitment and differentiation. Front Biosci. 2007;12:3068-92.

82. Baron R, Kneissel M. WNT signaling in bone homeostasis and disease: from human mutations to treatments. Nat Med. 2013;19(2):179-92. https://doi.org/10.1038/nm.3074.

83. Westendorf JJ, Kahler RA, Schroeder TM. Wnt signaling in osteoblasts and bone diseases. Gene. 2004;341:19-39. https://doi.org/10.1016/j. gene.2004.06.044.

84. Shin MK, Kim MK, Bae YS, Jo I, Lee SJ, Chung CP, et al. A novel collagenbinding peptide promotes osteogenic differentiation via $\mathrm{Ca}^{2+}$ / calmodulin-dependent protein kinase II/ERK/AP-1 signaling pathway in human bone marrow-derived mesenchymal stem cells. Cell Signal. 2008;20(4):613-24. https://doi.org/10.1016/j.cellsig.2007.11.012.

85. Habas R, Dawid IB, He X. Coactivation of Rac and Rho by Wnt/Frizzled signaling is required for vertebrate gastrulation. Genes Dev. 2003;17(2):295-309. https://doi.org/10.1101/gad.1022203.

86. de Sousa Abreu R, Penalva LO, Marcotte EM, Vogel C. Global signatures of protein and mRNA expression levels. Mol Biosyst. 2009;5(12):1512-26. https://doi.org/10.1039/b908315d.

87. Vogel C, Marcotte EM. Insights into the regulation of protein abundance from proteomic and transcriptomic analyses. Nat Rev Genet. 2012;13(4):227-32. https://doi.org/10.1038/nrg3185.

88. Maier T, Guell M, Serrano L. Correlation of mRNA and protein in complex biological samples. FEBS Lett. 2009;583(24):3966-73. https://doi. org/10.1016/j.febslet.2009.10.036.

89. Quang T, Marquez M, Blanco G, Zhao Y. Dosage and cell line dependent inhibitory effect of bFGF supplement in human pluripotent stem cell culture on inactivated human mesenchymal stem cells. PLOS ONE. 2014;9(1):e86031. https://doi.org/10.1371/journal.pone.0086031.

90. Carpenter AE, Jones TR, Lamprecht MR, Clarke C, Kang IH, Friman O, et al. Cell Profiler: image analysis software for identifying and quantifying cell phenotypes. Genome Biol. 2006;7(10):100. https://doi.org/10.1186/gb2006-7-10-r100 (Epub 2006/11/02). 